\title{
Novel and Polynuclear K- and Na-Based Superalkali Hydroxides as Superbases Better Than Li-Related Species and Their Enhanced Properties: An Ab Initio Exploration
}

\author{
Sarvesh Kumar Pandey* \\ Cite This: ACS Omega 2021, 6, 31077-31092 \\ Read Online
}

ABSTRACT: Hydroxides of superalkalis (particularly, K- and Narelated species) are shown for the first time to function as superbases. A new small series of hydroxides $\left(\mathrm{XM}_{n+1} \mathrm{OH}\right)$ is designed based on superalkali species $\left(\mathrm{XM}_{n+1}\right)$ where $\mathrm{M}(\mathrm{K}$ and $\mathrm{Na}$ ) is alkali metal atoms, $n$ is the maximal formal valence of the central atom $\mathrm{X}(\mathrm{F}, \mathrm{O}$, and $\mathrm{N})$, and $n \geq 1$. To probe whether such fascinating polynuclear superalkali hydroxides (SAHs), especially the $\mathrm{K}$ - and $\mathrm{Na}$-associated moieties are as basic as the representative alkali metal hydroxides $(\mathrm{KOH}, \mathrm{NaOH}$, and $\mathrm{LiOH})$ as well as similar Li-based SAHs, a comprehensive computational exploration (in the gas phase) has been reported using the framework of an ab

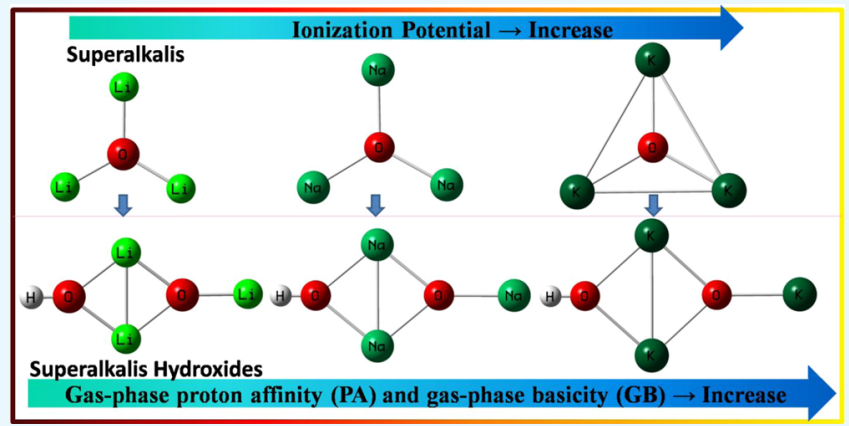
initio method. The ab initio calculations reveal that both the $\mathrm{K}$ and Na-related SAHs consisting of larger gas-phase proton affinity (PA) and gas-phase basicity (GB) values demonstrate stronger basic character compared to the $\mathrm{LiOH}$ and Li-based SAHs. However, the available SAHs act as strong bases as well as superbases; among the proposed $\mathrm{K}$ - and Na-based SAHs, remarkably, the $\mathrm{OK}_{3} \mathrm{OH}$ moiety having the highest PA (1168.4 kJ/mol) and GB $(1146.9 \mathrm{~kJ} / \mathrm{mol})$ values shows the evidence of the strongest basicity (i.e., superbase/hyperbase), which exceed enough $(\Delta \mathbf{P A}: 142.1$ $\mathrm{kJ} / \mathrm{mol}$ and $\Delta$ GB: $146.9 \mathrm{~kJ} / \mathrm{mol}$ ) the IUPAC-defined superbasicity threshold values (PA: $1026.3 \mathrm{~kJ} / \mathrm{mol}$ and GB: $1000 \mathrm{~kJ} / \mathrm{mol}$ ) of 1,8-bis(dimethylamino)naphthalene (DMAN). Furthermore, theoretical signatures have been predicted via the electronic structure calculation approach in probing the dissociation energy, ionization potential, electron affinity, HOMO-LUMO gap, and chemical hardness as well as the NCI plot and QTAIM tools are used for the bonding feature analysis and such parameters are well linked with the basicity analyzing parameters. In this study, the ab initio-based computational experiments provide some new insights into the basicity features and understanding of the structural and electronic features of a small series of designed K-and Na-related SAHs. Design and synthesis of such theoretically examined SAHs may pave alternative routes for the experimentally rewarding applications.

\section{INTRODUCTION}

Molecules having low ionization potentials (IPs) may play a crucial role in chemistry, and alkali metal atoms are quite important because of their very small IPs. In particular, superalkali species show remarkable features due to their lower IPs compared to those (5.39-3.89 eV) of the alkali metal atoms. ${ }^{1}$ Thus far, examination of superalkali species involves from small to medium size mono-, bi-, and polynuclear species and then unique superalkalis. Also, superalkalis with outstanding reducing properties have accomplished noteworthy progress earlier and have attracted more and more attention as well as great importance in chemistry. Such success lead to vast construction of new moieties as superalkalis. Recently, remarkable studies have been reported regarding the potential utilization of superalkalis but the practical application of such species yet persists as a challenge. Studies on the scope of superalkalis (especially, synthesis of the nonmetallic and polynuclear superalkali cations associated with diverse functional groups) and superhalogens have greatly expanded in approximately the past 15 years. ${ }^{2,3}$ Along with such progress, molecular modeling and designing of novel superbases from their simple building blocks are quite promising and are active areas of research and development; however, suitable selection of such model systems for a rational design and synthesis is still to be achieved by experimentalists. By acquiring more pieces of information as well as new insights into the conspicuous geometrical and electronic features of such systems, various theoretical and experimental examinations have been carried out. $^{4-8}$ Studies on the building blocks of super salts and their related systems like encapsulated superalkalis inside fullerene can also be seen in the literature. ${ }^{8-10}$

Received: August 14, 2021

Accepted: October 8, 2021

Published: November 11, 2021 
A variety of experiments on molecular species like $\mathrm{XLi}_{2}(\mathrm{X}=\mathrm{F}$, $\mathrm{Cl}, \mathrm{Br}$, and I) ${ }^{11-13} \mathrm{OM}_{3}(\mathrm{M}=\mathrm{Li}, \mathrm{Na}$, and $\mathrm{K}),{ }^{14-16} \mathrm{NLi}_{4},{ }^{4} \mathrm{BLi}_{n}$ $(n=1-7),{ }^{17}$ etc. has been reported. As alkali metal and alkali earth metal oxides and their hydroxides (in the gaseous state) are reported to be the strongest bases, ${ }^{18}$ hitherto, a large range of inorganic as well as ionic and covalent organic bases can be viewed, including the bases having high proton affinities (socalled superbases). ${ }^{19-22}$ Alder's 1,8-bis(dimethylamino)naphthalene (DMAN) compound (in the gas phase) with proton enthalpy equal to or greater than $1026.3 \mathrm{~kJ} / \mathrm{mol}$ has been referred a superbase as per recommendation by the International Union of Pure and Applied Chemistry (IUPAC) definition. ${ }^{20}$ Numerous efforts have been devoted to obtaining experimental findings for synthesizing superalkalis and their related compounds, which have been described along with the synthesis of superhalogens/hyperhalogens. ${ }^{12,23-27}$ For exploring the potential-reducing capabilities of such type of innovative species and synthesis of various charge-transfer (CT) salts, numerous attempts have been made incessantly. ${ }^{5,28}$ Theoretical characterization of a new type of superhalogen-(super)alkali compound $\mathrm{BF}_{4}{ }^{-} \mathrm{M}\left(\mathrm{M}=\mathrm{Li}, \mathrm{FLi}_{2}, \mathrm{OLi}_{3}\right.$, and $\left.\mathrm{NLi}_{4}\right)$ has also been reported, which revealed the nonlinear optical properties of such superatom compounds. ${ }^{29}$

Despite the abovementioned achievements, there is still room for improvement and many attempts are still needed to design and characterize methods for acquiring innovative superalkali moieties to enrich the superalkali family. To the best of our knowledge, designing and theoretical characterization (in terms of capability to function as superbases/hyperbases) of $\mathrm{XM}_{n+1} \mathrm{OH}$ (where $\mathrm{M}=\mathrm{K}$ and $\mathrm{Na}$ ) have not been explored previously. In the $\mathrm{XM}_{n+1}$ segment of the $\mathrm{XM}_{n+1} \mathrm{OH}$ species, " $n$ " refers to the number of valence electrons needed to complete the electronic shell of the electronegative $\mathrm{X}$ atom (F, O, and $\mathrm{N})$, and hence, one extra alkali metal atom $(\mathrm{M})(\mathrm{M}=\mathrm{K}, \mathrm{Na}$, and $\mathrm{Li})$ will provide an extra valence electron for the electronic shell of the $\mathrm{X}$ atom. Afterward, a high tendency to drop one valence electron is demonstrated by the $\mathrm{XM}_{n+1}$ molecular system for constructing a very stable cation having positive charges spread over all the " $n+$ 1 " alkali atoms (M). The goal of research work is twofold: first, a small series of hydroxide of superalkalis especially K- and Nabased SAHs has mainly been considered and efforts have been done in obtaining new insights into the absolute gas-phase proton affinity (PA) and intrinsic gas-phase basicity (GB) of these superbases and then comparing with the $\mathrm{LiOH}$ and $\mathrm{Li}$ related SAHs. Second, the calculated PA and GB parameters are well linked to some very important and useful analyzed electronic feature-based outcomes . It is contemplated the possibility that the superalkalis, as well as related species, may be brought to play as the core for synthesizing novel superhalogensuperalkali compounds and offering fascinating electronic features. $^{27}$

In this study, because of the importance of cation/molecule interactions in chemical and biochemical processes, a new series of novel and strong bases $\mathrm{XM}_{n+1} \mathrm{OH}$ SAHs (such as $\mathrm{FK}_{2} \mathrm{OH}$, $\mathrm{OK}_{3} \mathrm{OH}, \mathrm{NK}_{4} \mathrm{OH}, \mathrm{FNa}_{2} \mathrm{OH}, \mathrm{ONa}_{3} \mathrm{OH}$, and $\mathrm{NNa}_{4} \mathrm{OH}$ ) have been tentatively designed and examined, including the corresponding fundamental bases $\mathrm{KOH}$ and $\mathrm{NaOH}$ along with $\mathrm{LiOH}$ and its allied SAHs acting as strong bases and superbases. The foremost advantage of designing and characterizing theoretically the K- and Na-related SAHs is that these species show their stronger basicity behavior (all act as superbases) than the earlier reported $\mathrm{LiOH}$ as well as its related SAHs. ${ }^{30}$ Among all the $\mathrm{XM}_{n+1} \mathrm{OH}$ species, the K-related SAHs, especially, the
$\mathrm{OK}_{3} \mathrm{OH}$ moiety consisting of the highest PA and GB values, manifest the strongest basic character. The draught structures of the K- and Na-based moieties show a clear signature of their higher basic character when such species are constructed from a higher number of alkali metals (i.e., superatoms) and hydroxides (OH group). Moreover, attempts have been put forward to obtain some profound and useful insights into the bonding and nonbonding features with the deployment of the noncovalent interaction (NCI) plot and Bader's quantum theory of atoms in molecules (QTAIM) tools. Several reports on the application of the NCI plot and QTAIM-based topological parameters can be seen in the literature. ${ }^{31-34}$

\section{THEORY AND COMPUTATIONS}

The selection of a quantum chemical calculation (QCC) approach that precisely portrays the basicity-related features is an intricate challenge. The choice of an ab initio method for bonding between the alkali metal atom $\left(\mathrm{XM}_{n+1}\right)$ and hydroxyl $(\mathrm{OH})$ group of the $\mathrm{K}$ - and Na-related SAHs is based on the fact that for the alkali metal and alkaline earth metal oxides and hydroxides, ab initio calculations suitably predict the energetic features and also the structural/geometrical outcomes may be in uniformly close agreement with the available experimental data. $^{35}$ The QCC-based optimized (equilibrium) geometries and vibrational harmonic frequencies have been determined by employing the second-order Møller-Plesset (MP2) perturbation theory ${ }^{36}$ in conjugation with a standard split valence basis set including diffuse and polarization functions and the 6-311+ $+\mathrm{G}(\mathrm{d}, \mathrm{p})$ basis set using the Gaussian $09^{37}$ electronic structure calculation program.

A hypothetical gas-phase protonation reaction has been expressed in eq 1 for evaluating the basicity of diverse $\mathrm{XM}_{n+1} \mathrm{OH}$ hydroxides of $\mathrm{K}-, \mathrm{Na}-$, and Li-related species.

$$
\mathrm{XM}_{n+1} \mathrm{OH}+\mathrm{H}^{+} \rightarrow \mathrm{XM}_{n+1} \mathrm{OH}_{2}^{+}
$$

where $\mathrm{XM}_{n+1}$ are $\mathrm{FK}_{2}, \mathrm{OK}_{3}, \mathrm{NK}_{4}, \mathrm{FNa}_{2}, \mathrm{ONa}_{3}, \mathrm{NNa}_{4}, \mathrm{FLi}_{2}, \mathrm{OLi}_{3}$, and $\mathrm{NLi}_{4}$.

The equation given below (eq 2) describes the accurate gasphase PA and intrinsic GB of a base (B) (here defined as $\mathbf{B}=$ $\mathrm{XM}_{n+1} \mathrm{OH}$ ) and understandably the gas-phase basicity of a neutral base (B) is equal to the acidity of its conjugate acid $\left(\mathbf{B H}^{+}\right)$(i.e., $\mathbf{B H}^{+}=\mathrm{XM}_{n+1} \mathrm{OH}_{2}^{+}$). It should be noted that high values of PA and GB parameters signify higher basicity. For analyzing two very important and useful parameters PA and GB of the designed $\mathrm{K}$ - and Na-based SAHs $\left(\mathrm{XM}_{n+1} \mathrm{OH}\right)$ and their protonated forms $\left(\mathrm{XM}_{n+1} \mathrm{OH}_{2}^{+}\right)$, the enthalpy $(\Delta H)$ and Gibbs free energy $(\Delta G)$ of the given below reaction have been determined

$$
\mathbf{B H}^{+}(\mathrm{g}) \rightleftharpoons \mathbf{B}(\mathrm{g})+\mathbf{H}^{+}(\mathrm{g}) \mathbf{P A}=\Delta H \text { and } \mathbf{G B}=\Delta G
$$

The enthalpy $(\Delta H)$ and Gibbs free energy $(\Delta G)$ for the proton $\left(\mathbf{H}^{+}\right)$have been acquired from the literature. ${ }^{38}$

It is also worth mentioning that the following equation (eq 3 ) was employed for analyzing the energy of ionic dissociation of the $\mathrm{XM}_{n+1} \mathrm{OH}$ species into their constituting $\mathrm{XM}_{n+1}{ }^{+}$and $\mathrm{OH}^{-}$ moieties.

$$
\Delta E=E\left(\mathrm{XM}_{n+1}^{+}\right)+E\left(\mathrm{OH}^{-}\right)-E\left(\mathrm{XM}_{n+1} \mathrm{OH}\right)
$$

where the $E(. .$.$) values refer to the total electronic energy of the$ corresponding species with the zero-point correction. 

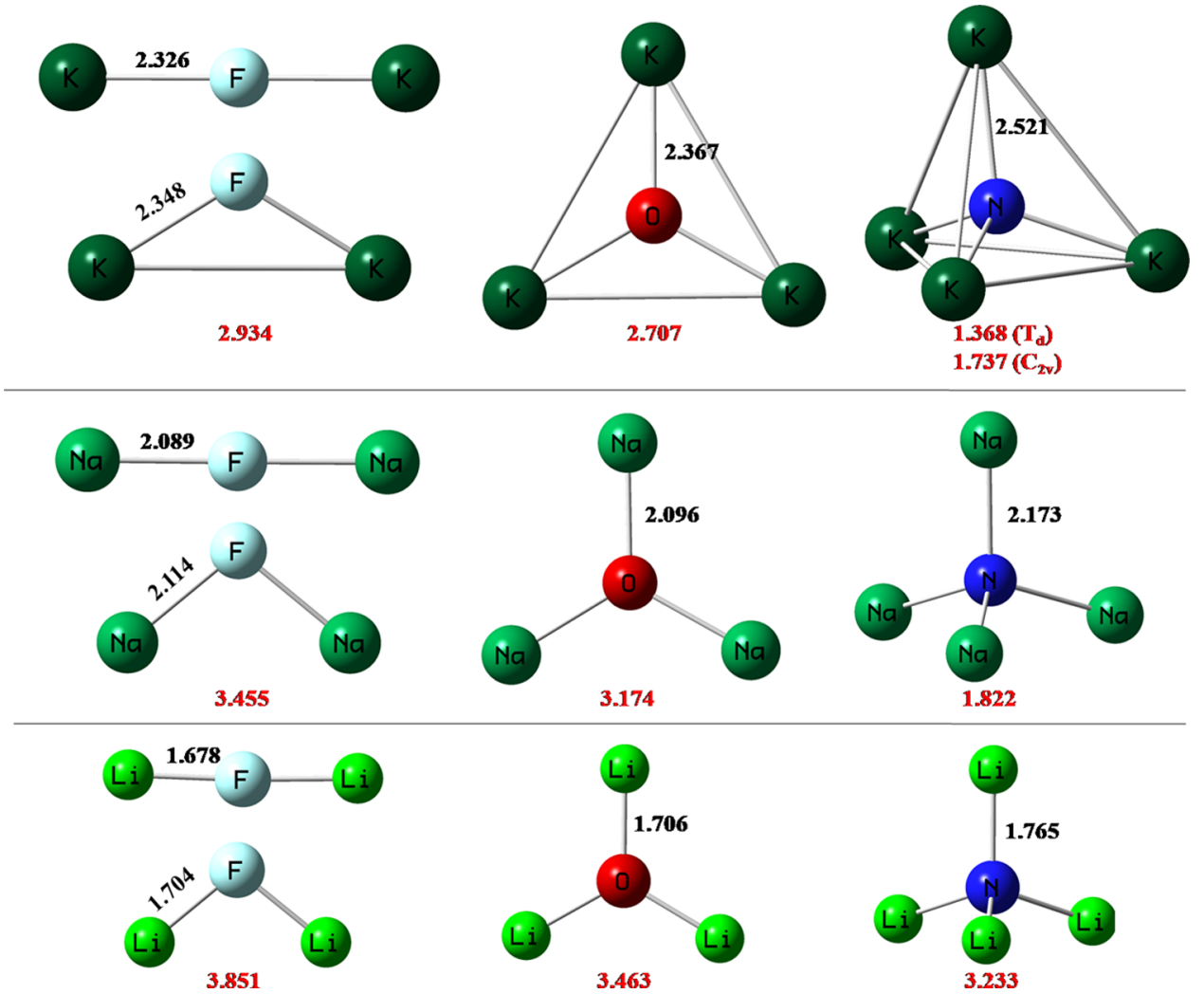

Figure 1. Equilibrium structures of the $\mathrm{XM}_{n+1}$ K-related (top), Na-related (middle), and Li-related (bottom) superalkali neutral species. The bond lengths (black color in bold) and IPs (red color in bold) are given in $\AA$ and eV, respectively.

Table 1. Bond Lengths and IPs of the Neutral Superalkali $\mathrm{XM}_{n+1}\left(\mathrm{FK}_{2}, \mathrm{OK}_{3}, \mathrm{NK}_{4}, \mathrm{FNa}_{2}, \mathrm{ONa}_{3}, \mathrm{NNa}_{4}, \mathrm{FLi}_{2}, \mathrm{OLi}_{3}\right.$, and NLi $\left.\mathrm{Ni}_{4}\right)$ Species Using the MP2/6-311++G(d, p) Level of Theory along with the Natural Charges on the Atoms

\begin{tabular}{|c|c|c|c|c|c|c|}
\hline \multirow{2}{*}{$\begin{array}{l}\text { species } \\
\mathrm{K}\end{array}$} & \multirow{2}{*}{$\begin{array}{l}\text { symmetry } \\
\text { - }\end{array}$} & \multirow{2}{*}{ geometry } & \multirow{2}{*}{$\begin{array}{l}\text { bond length }(\AA) \\
\text { - }\end{array}$} & \multirow{2}{*}{$\begin{array}{c}\mathrm{IP}(\mathrm{eV}) \\
4.235\end{array}$} & \multicolumn{2}{|c|}{ natural charge (e) } \\
\hline & & & & & - & - \\
\hline $\mathrm{FK}_{2}$ & $\mathrm{C}_{2 \mathrm{v}}$ & bent (V shape) & $2.348(\mathrm{~K}-\mathrm{F})$ & 2.934 & $F(-0.979 e)$ & $\mathrm{K}(0.49 \mathrm{e})$ \\
\hline $\mathrm{OK}_{3}$ & $\mathrm{D}_{3 \mathrm{~h}}$ & trigonal planar & $2.367(\mathrm{~K}-\mathrm{O})$ & 2.707 & $\mathrm{O}(-1.908 \mathrm{e})$ & $\mathrm{K}(0.636 \mathrm{e})$ \\
\hline \multirow[t]{2}{*}{$\mathrm{NK}_{4}$} & $\mathrm{~T}_{\mathrm{d}}^{a}$ & tetrahedral & $2.686(\mathrm{~K}-\mathrm{N})$ & 1.368 & $\mathrm{~N}(-2.679 \mathrm{e})$ & $\mathrm{K}(0.671 \mathrm{e})$ \\
\hline & $\mathrm{C}_{2 \mathrm{v}}(\mathrm{TS})$ & tetrahedral & $2.521(\mathrm{~K}-\mathrm{N})$ & 1.737 & $\mathrm{~N}(-2.671 \mathrm{e})$ & $\mathrm{K}(0.668 \mathrm{e})$ \\
\hline $\mathrm{Na}$ & - & - & - & 4.944 & - & - \\
\hline $\mathrm{FNa}_{2}$ & $\mathrm{C}_{2 \mathrm{v}}$ & bent (V shape) & $2.114(\mathrm{Na}-\mathrm{F})$ & 3.455 & $\mathrm{~F}(-0.978 \mathrm{e})$ & $\mathrm{Na}(0.489 \mathrm{e})$ \\
\hline $\mathrm{ONa}_{3}$ & $\mathrm{D}_{3 \mathrm{~h}}$ & trigonal planar & $2.096(\mathrm{Na}-\mathrm{O})$ & 3.174 & $\mathrm{O}(-1.915 \mathrm{e})$ & $\mathrm{Na}(0.638 \mathrm{e})$ \\
\hline $\mathrm{NNa}_{4}$ & $\mathrm{~T}_{\mathrm{d}}$ & tetrahedral & $2.173(\mathrm{Na}-\mathrm{N})$ & 1.822 & $\mathrm{~N}(-1.805 \mathrm{e})$ & $\mathrm{Na}(0.451 \mathrm{e})$ \\
\hline $\mathrm{Li}$ & - & - & - & 5.339 & - & - \\
\hline $\mathrm{FLi}_{2}$ & $\mathrm{C}_{2 \mathrm{v}}$ & bent (V shape) & $1.704(\mathrm{Li}-\mathrm{F})$ & 3.851 & $\mathrm{~F}(-0.941 \mathrm{e})$ & $\mathrm{Li}(0.471 \mathrm{e})$ \\
\hline $\mathrm{OLi}_{3}$ & $\mathrm{D}_{3 \mathrm{~h}}$ & trigonal planar & $1.706(\mathrm{Li}-\mathrm{O})$ & 3.463 & $\mathrm{O}(-1.823 \mathrm{e})$ & $\mathrm{Li}(0.607 \mathrm{e})$ \\
\hline $\mathrm{NLi}_{4}$ & $\mathrm{~T}_{\mathrm{d}}$ & tetrahedral & $1.765(\mathrm{Li}-\mathrm{N})$ & 3.233 & $\mathrm{~N}(-2.397 \mathrm{e})$ & $\mathrm{Li}(0.599 \mathrm{e})$ \\
\hline
\end{tabular}

For the chemical bond study, the electron density (ED)-based chemical bonding (including the weakest bonding as well as nonbonding interatomic interactions) and structural feature analyses of such species have been explored using the wavefunction are conducted with the deployment of Bader's powerful QTAIM tool. ${ }^{39}$ The energetic and topological features in the bond critical point (BCP) are utilized for exploring the type, nature, and strength of the bonding and nonbonding interactions (NBIs)/NCIs. The ED distribution function, $\rho(r)$, and the wavefunction-based Laplacian, $\nabla^{2} \rho(r)$, can be analyzed for the equilibrium geometry of the probing species by the QTAIM approach with the help of the AIMAll package. ${ }^{40}$ The natural bond orbital (NBO) analysis was also employed in evaluating the natural atomic charges wherever needed. ${ }^{41}$ To look into the type, nature, and strength of interactions involved in all the Na- and K-related species, the NCI plot technique was applied in the framework of Multiwfn (version 3.7) package. ${ }^{42,43}$

\section{RESULTS AND DISCUSSION}

$X_{n+1}$ Species. We considered the optimized structures and properties of the building blocks (i.e., referred as the superalkalis: $\left.\mathrm{XM}_{n+1}\right)$ as the starting materials. The optimized geometries of the $\mathrm{XM}_{n+1}$ species are shown in Figure 1 along with some chosen structural parameters particularly, the bond lengths. For example, Figure 1 presents the optimized structures of the neutral K- and Na-related superalkalis $\left(\mathrm{XM}_{n+1}: \mathrm{FK}_{2}, \mathrm{OK}_{3}\right.$, 

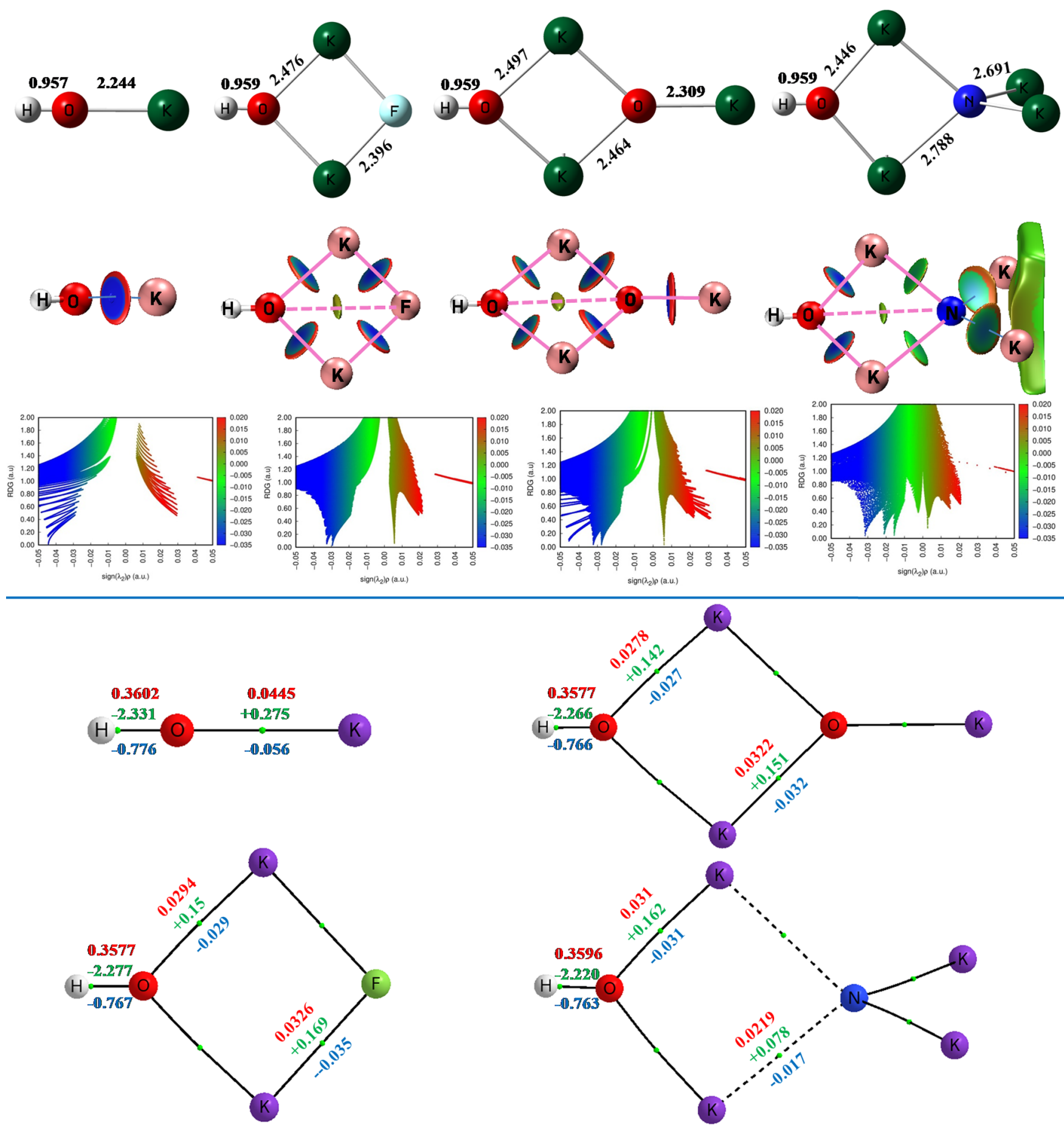

Figure 2. Equilibrium structures (top), NCI $3 \mathrm{D}$ isosurfaces (middle), and NCI $2 \mathrm{D}$ scatter plots (bottom) of the $\mathrm{KOH}$ and $\mathrm{XK}_{n+1} \mathrm{OH}$ bases $\left(\mathrm{XM}_{n+1}=\right.$ $\mathrm{FK}_{2}, \mathrm{OK}_{3}$, and $\left.\mathrm{NK}_{4}\right)$ are provided above the blue line. The bond lengths are given in $\AA$. QTAIM pictures and topological parameters $\left(\rho, \nabla^{2} \rho, V\right)$ of the $\mathrm{KOH}$ and $\mathrm{XK}_{n+1} \mathrm{OH}$ species are provided below the blue line.

$\mathrm{NK}_{4}, \mathrm{FNa}_{2}, \mathrm{ONa}_{3}$, and $\mathrm{NNa}_{4}$ ) where the equilibrium structures of the neutral Li-related superalkalis $\mathrm{XLi}_{n+1}\left(\mathrm{FLi}_{2}, \mathrm{OLi}_{3}\right.$, and $\mathrm{NLi}_{4}$ ) have also been displayed for the sake of convenience and comparison purposes. One can perceive that the equilibrium/ optimized structures of the F-, O-, and N-substituted superalkalis are in bent $\left(\mathrm{C}_{2 \mathrm{v}}\right)$, trigonal planar $\left(\mathrm{D}_{3 \mathrm{~h}}\right)$, and tetrahedral $\left(\mathrm{T}_{\mathrm{d}}\right)$ shapes, respectively. Moreover, the neutral superalkalis $\left(\mathrm{FLi}_{2}, \mathrm{FNa}_{2}\right.$, and $\left.\mathrm{FK}_{2}\right)$ and their particular cations $\left(\mathrm{FLi}_{2}{ }^{+}, \mathrm{FNa}_{2}{ }^{+}\right.$, and $\mathrm{FK}_{2}^{+}$) are in bent and linear shapes, respectively.
To analyze the protonation behavior/capability of the K- and Na-related species for establishing the superalkali species, the IPs have been analyzed by evaluating the difference between the energies of the ground states of the neutral superalkali atoms (i.e., superalkalis) and their respective cations. The bond lengths and IPs of all the neutral superalkali species $\left(\mathrm{XM}_{n+1}: \mathrm{FK}_{2}, \mathrm{OK}_{3}\right.$, $\mathrm{NK}_{4} ; \mathrm{FNa}_{2}, \mathrm{ONa}_{3}, \mathrm{NNa}_{4} ; \mathrm{FLi}_{2}, \mathrm{OLi}_{3}$, and $\mathrm{NLi}_{4}$ ) along with the natural charges on the atoms are listed in Table 1 . The expected order of bond lengths of the F-, O-, and N-related species is $\mathrm{FK}_{2}$ (2.348) $>\mathrm{FNa}_{2}(2.114)>\mathrm{FLi}_{2}$ (1.704); $\mathrm{OK}_{3}$ (2.367) $>\mathrm{ONa}_{3}$ 

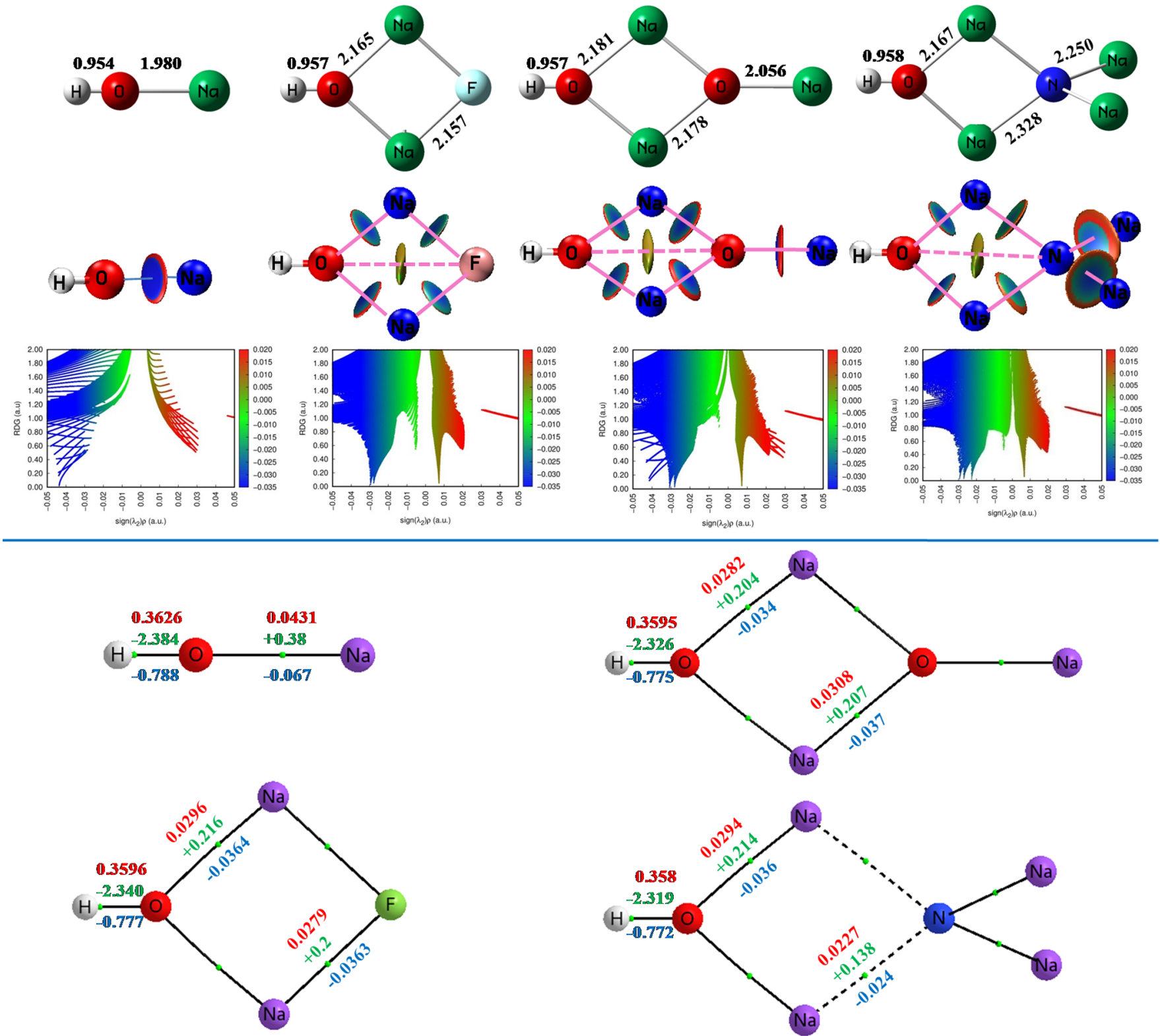

Figure 3. Equilibrium structures (top), $\mathrm{NCI} 3 \mathrm{D}$ isosurfaces (middle), and $\mathrm{NCI} 2 \mathrm{D}$ scatter plots (bottom) of the $\mathrm{NaOH}$ and $\mathrm{XNa} a_{n+1} \mathrm{OH}_{\text {bases }}\left(\mathrm{XM}_{n+1}\right.$ $=\mathrm{FNa}_{2}, \mathrm{ONa}_{3}$, and $\left.\mathrm{NNa}_{4}\right)$ are provided above the blue line. The bond lengths are given in $\AA$. QTAIM pictures and topological parameters $\left(\rho, \nabla^{2} \rho, V\right)$ of the $\mathrm{NaOH}$ and $\mathrm{XNa}_{n+1} \mathrm{OH}$ species are provided below the blue line.

(2.096) > $\mathrm{OLi}_{3}(1.706)$; and $\mathrm{NK}_{4}(2.521)>\mathrm{NNa}_{4}(2.173)>$ $\mathrm{NLi}_{4}$ (1.765) (in $\AA$ ), respectively, which clearly seem to be dependent on the size of alkali metals $(\mathrm{K}>\mathrm{Na}>\mathrm{Li})$ and the outcomes of the $\mathrm{NX}_{4}$-related species are in good agreement with the previous studies. ${ }^{44}$

It is interesting to note that in the case of $\mathrm{NK}_{4}$ superalkali species, using the MP2/6-31+G(d,p) and MP2/6-311++G(d, p) methods, it was found that the cation $\left(\mathrm{NK}_{4}^{+}\right)$species shows a $\mathrm{T}_{\mathrm{d}}$ structure having a minima in the potential energy surface (PES), whereas in terms of symmetry, the former method gives a $\mathrm{T}_{\mathrm{d}}$ symmetry (having the minima in the PES) and the latter one provides a $\mathrm{C}_{2 \mathrm{v}}$ symmetry (showing a transition state (TS) in the PES) for the neutral $\mathrm{NK}_{4}$ moiety while both approaches give a $\mathrm{T}_{\mathrm{d}}$ symmetry structure for the same. One of the excellent features of all nine superalkalis is that all of have lower IP values $\left(\mathrm{NK}_{4}(1.368 \mathrm{eV})<\mathrm{NNa}_{4}(1.822 \mathrm{eV})<\mathrm{NLi}_{4}(3.233 \mathrm{eV}) ; \mathrm{FK}_{2}\right.$ $(2.934 \mathrm{eV})<\mathrm{FNa}_{2}(3.455 \mathrm{eV})<\mathrm{FLi}_{2}(3.851 \mathrm{eV})$; and $\mathrm{OK}_{3}$ $\left.(2.707 \mathrm{eV})<\mathrm{ONa}_{3}(3.174 \mathrm{eV})<\mathrm{OLi}_{3}(3.463 \mathrm{eV})\right)$ compared to the earlier highlighted respective alkali metal atoms $(\mathrm{K}, \mathrm{Na}$, and $\mathrm{Li}$ ) with IPs in the range of 5.39-3.89 eV and such outcomes are less adequate to ascertain their superalkali potentials. ${ }^{1,44}$ The analyzed natural charges $(Q)$ on the $\mathrm{XM}_{n+1}$ species, for instance, the charges on the $F$ and $\mathrm{M}$ atoms $\left(Q_{F}, Q_{M}\right)$ of the $F_{2}$ neutral species, $\mathrm{FK}_{2}(-0.979,0.49)>\mathrm{FNa}_{2}(-0.978,0.489)>\mathrm{FLi}_{2}$ $(-0.941,0.471)$, shown in Table 1 also favor the smooth construction of the superalkali-based compounds.

$\mathrm{KOH}$ and $\mathrm{XK}_{n+1} \mathrm{OH}$ Species. As superbases are of theoretical interest and potentially important in organic synthesis, ${ }^{45,46}$ a new series of fascinating and interesting Kand Na-related hydroxides of the superalkalis has been designed and computational experiments were performed for the theoretical characterization. A total of eight hydroxide species has been considered with two sets: set 1 consisting of K-based superalkalis (see Figure 2) and set 2 consisting of Na-based 

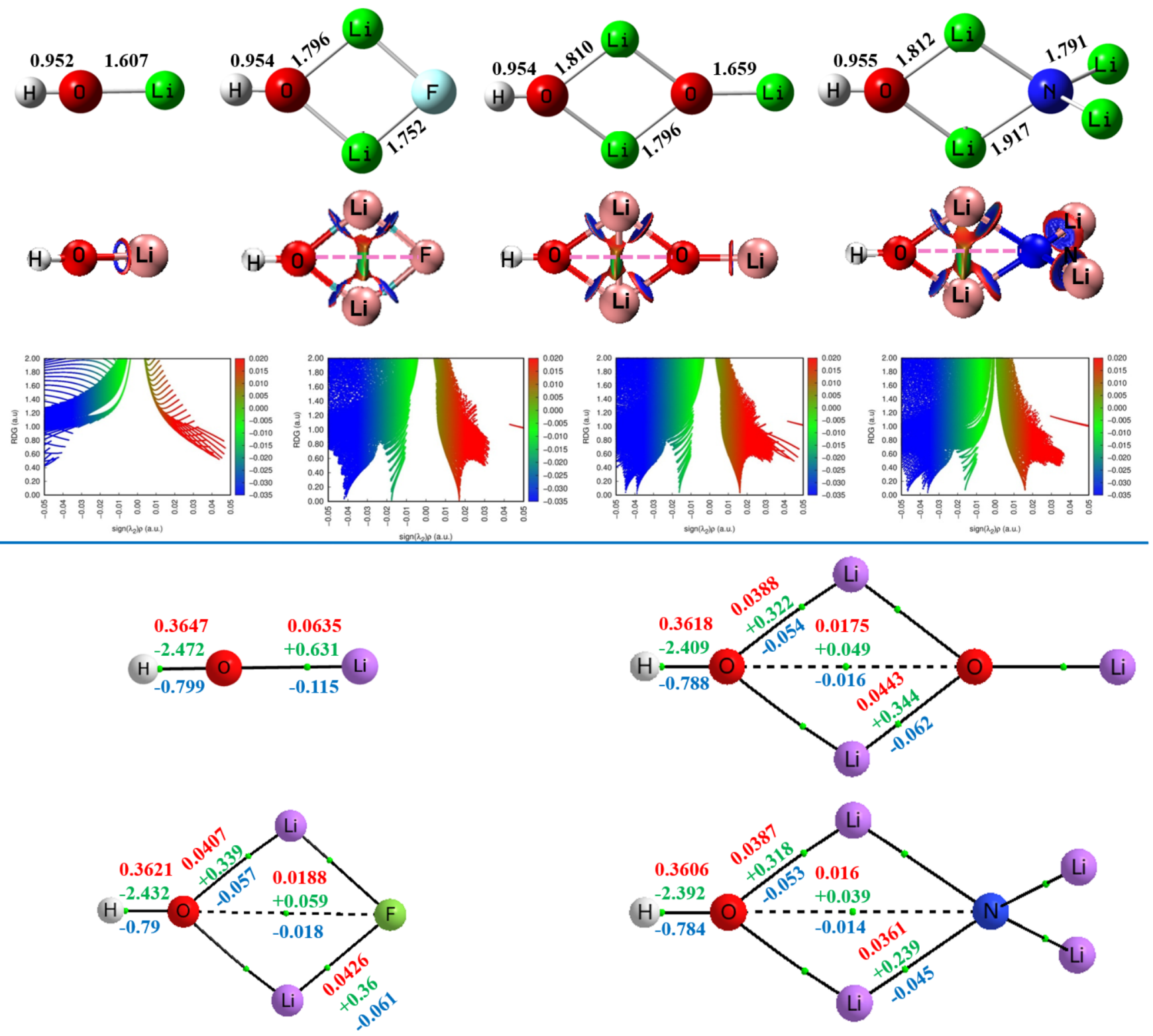

Figure 4. Equilibrium structures (top), NCI 3D isosurfaces (middle), NCI $2 \mathrm{D}$ scatter plots (bottom) of the LiOH and XLi ${ }_{n+1} \mathrm{OH}_{\text {bases }}\left(\mathrm{XLi}_{n+1}=\mathrm{FLi}_{2}\right.$, $\mathrm{OLi}_{3}$, and $\left.\mathrm{NLi}_{4}\right)$ are provided above the blue line. The bond lengths are given in $\AA$. QTAIM pictures and topological parameters $\left(\rho, \nabla^{2} \rho, V\right)$ of the $\mathrm{LiOH}$ and $\mathrm{XLi}_{n+1} \mathrm{OH}$ species are provided below the blue line.

superalkalis (see Figure 3) and each set having four hydroxides, and a third set with the Li-related species (see Figure 4) also consists of four similar hydroxides. For example, the first set of the K-related $\left(\mathrm{XK}_{n+1} \mathrm{OH}\right) \mathrm{SAH}$ optimized/equilibrium structures has three species $\mathrm{FK}_{2} \mathrm{OH}, \mathrm{OK}_{3} \mathrm{OH}$, and $\mathrm{NK}_{4} \mathrm{OH}$ including the fundamental base $\mathrm{KOH}$. Various geometries were scanned in finding out the appropriate $\mathrm{K}$ - and Na-related SAHs along with the Li-related species $\left(\mathrm{XLi}_{n+1} \mathrm{OH}: \mathrm{FLi}_{2} \mathrm{OH}, \mathrm{OLi}_{3} \mathrm{OH}\right.$, and $\left.\mathrm{NLi}_{4} \mathrm{OH}\right)$. As shown in Figure $2\left(\mathrm{XK}_{n+1} \mathrm{OH}\right)$ and Figure 3 $\left(\mathrm{XNa}_{n+1} \mathrm{OH}\right)$, both sets of the species have $\mathrm{C}_{2 \mathrm{v}}$ symmetry structures and the hydroxyl $(-\mathrm{OH})$ group involved therein is connected to the superalkalis through two alkali metal atoms (i.e., the $\mathrm{OH}$ group is linked to two potassium atoms in the $\mathrm{XK}_{n+1} \mathrm{OH}$ case forming a four-membered ring) corresponding to the minimum energy geometries.

As shown in Figure 2, for the optimized parameters of a linear $\mathrm{KOH}$ equilibrium ( $C_{\infty \mathrm{v}}$ symmetry) structure, the $\mathrm{O}-\mathrm{K}$ and $\mathrm{O}-$ $\mathrm{H}$ bond lengths are 2.244 and $0.957 \AA$, respectively, which are close to their corresponding experimental outcomes $(\mathrm{O}-\mathrm{K}$ : $2.212 \AA$ and $\mathrm{O}-\mathrm{H}: 0.912 \AA) .{ }^{47}$ Two structures of the $\mathrm{XK}_{n+1} \mathrm{OH}$ $\left(\mathrm{FK}_{2} \mathrm{OH}\right.$ and $\left.\mathrm{OK}_{3} \mathrm{OH}\right)$ have been observed to be planar except the $\mathrm{NK}_{4} \mathrm{OH}$ in which the $\mathrm{NK}_{2}$ segment (i.e., $\mathrm{K}-\mathrm{N}-\mathrm{K}$ having the $\mathrm{N}-\mathrm{K}$ bond length as $2.691 \AA \AA$ in V shape) lying at right side from the center of the ring (terminal NK2 existing at right side) is perpendicular to the $\mathrm{H}-\mathrm{O}<\mathrm{K}_{2}$ fragment (i.e., O-K: $2.446 \AA$ and $\mathrm{O}-\mathrm{H}: 0.959 \AA$ ) located on the left side from the center of the ring. From Figure 2, it can be seen that the $\mathrm{X}-\mathrm{K}$ bond lengths associated with the cyclic form of the $\mathrm{XK}_{n+1} \mathrm{OH}$ SAHs $(\mathrm{F}-\mathrm{K}$ in $\mathrm{FK}_{2} \mathrm{OH}: 2.396 \AA$, $\mathrm{O}-\mathrm{K}$ in $\mathrm{OK}_{3} \mathrm{OH}: 2.464 \AA$, and $\mathrm{N}-\mathrm{K}$ in $\mathrm{NK}_{4} \mathrm{OH}: 2.788 \AA$ ) are higher than those in the respective superalkalis (see Figure 1) $\left(\mathrm{F}-\mathrm{K}\right.$ in $\mathrm{FK}_{2}: 2.348 \AA, \mathrm{O}-\mathrm{K}$ in $\mathrm{OK}_{3}$ : $2.367 \AA$, and $\mathrm{N}-\mathrm{K}$ in $\left.\mathrm{NK}_{4}: 2.521 \AA\right)$ as well as $\mathrm{KOH}(\mathrm{O}-\mathrm{K}$ : $2.244 \AA$ ). Such findings are possible because of the CT phenomenon occurring in different $\mathrm{K}$ atoms of the SAHs to the hydroxyl $(\mathrm{OH})$ group and also the electronegative atoms (i.e., F, $\mathrm{O}$, and $\mathrm{N}$ ) involved therein. Using the $\mathrm{NBO}$ approach, the 
natural charges $\left(Q_{K}\right)$ on the $\mathrm{K}$ atoms of the $\mathrm{FK}_{2} \mathrm{OH}, \mathrm{OK}_{3} \mathrm{OH}$, and $\mathrm{NK}_{4} \mathrm{OH}$ have been calculated as $0.976 \mathrm{e}, 0.955 \mathrm{e}$, and $0.903 \mathrm{e}$, respectively (note that the $Q_{K}$ on the bridged $K$ atoms are shown here) and such a decreasing trend is due to the enhanced $\mathrm{X}-\mathrm{K}$ bond lengths with the $\mathrm{O}-\mathrm{K}$ bond length of $\mathrm{KOH}(\mathrm{KOH}(2.244$ $\AA)<\mathrm{FK}_{2} \mathrm{OH}(\mathrm{F}-\mathrm{K}: 2.396 \AA)<\mathrm{OK}_{3} \mathrm{OH}(\mathrm{O}-\mathrm{K}: 2.464 \AA)<$ $\mathrm{NK}_{4} \mathrm{OH}\left(\mathrm{N}-\mathrm{K}: 2.788 \AA\right.$ ) ) altering from $\mathrm{FK}_{2} \mathrm{OH}$ to $\mathrm{NK}_{4} \mathrm{OH}$ species.

The NCI-reduced density gradient (NCI-RDG) tool has been used for the identification and graphical visualization of the bonding (i.e., covalent) and nonbonding (i.e., ionic and NCIs like $\mathrm{H}$-bonds, and van der Waals (vdW) interactions region(s) as well as for probing their strength. ${ }^{31,33,48}$ Usually, very strong attractive interactions are shown by localized blue lentils along with weak vdW interactions characterized by delocalized green regions. Color schemes provide comprehensive information about the NCIs. ${ }^{42}$ The RDG isosurface (2D scatter plot) shown on the horizontal axis ranges from -0.05 to +0.05 . On the horizontal axis (between -0.05 and +0.05 ), favorable (bonding and nonbonding) interactions emerge on the left side while unfavorable interactions emerge on the right side, and the extremely weak vdW interactions are close to zero (for instance, see the $2 \mathrm{D}$ scatter plot shown in Figure 3 (just above the light blue color horizontal line) for $\mathrm{XNa}_{n+1} \mathrm{OH}$ species). The colored surfaces of all the SAHs have been shown on the vertical axis (right side) in a red-green-blue scale via $\Omega(r)$ values ranging from -0.035 to +0.02 au (see Figure 3 ). The higher-density values $(\Omega(r)<0)$ show stronger attractive interactions, which are clarified by the meticulous depiction of the NCI technique, whereas repulsive interactions can be seen by the very lowdensity values $(\Omega(r)>0)$. For the sake of convenience and clarity, consider the $\mathrm{NK}_{4} \mathrm{OH}$ species in which the blue spike (between -0.03 and $-0.04 \mathrm{au}$ ) in the NCI 2D scatter plot and blue lentils in the $3 \mathrm{D}$ isosurface show strong $\mathrm{O}-\mathrm{K}$ interactions adjacent to the $\mathrm{O}-\mathrm{H}$ covalent bond. This structure also shows weak $\mathrm{N}-\mathrm{K}$ bonding interactions with respect to the $\mathrm{O}-\mathrm{K}$ interaction indicated by the dark green disc shape (in the $3 \mathrm{D}$ isosurface map) in the ring bond and dark green spikes in the $2 \mathrm{D}$ scatter plot (between -0.015 and $-0.025 \mathrm{au}$ ), which appear to confirm its weak metal-nonmetal bonding feature similar to a very strong $\mathrm{H}$-bonding interaction. Moreover, the NCI plot of the $\mathrm{NK}_{4} \mathrm{OH}$ base shows much stronger $\mathrm{N}-\mathrm{K}$ bonding interactions located at the terminal $\mathrm{N}-\mathrm{K}$ bonds (two greenish-blue color discs in the 3D isosurfaces) compared to those of the ring $\mathrm{N}-\mathrm{K}$ bonds (two dark green color discs in the $3 \mathrm{D}$ isosurfaces), which can clearly be verified by the QTAIM picture (vide infra). A small light green-colored peak (2D scatter plot ranging between 0 and $0.005 \mathrm{au}$ ) and a small light green disc lying at the center of the ring (3D isosurface map) can also be seen in Figure 3, which reveal the vdW (extremely weak) interaction between the two electronegative $\mathrm{O}$ and $\mathrm{N}$ atoms (i.e., a bond path as $\mathrm{O} \cdots \mathrm{N}) \cdot{ }^{31,33}$ One can see much weaker $\mathrm{N}-\mathrm{K}$ bonding interactions (i.e., both ring and terminal bonds) (example of $\mathrm{X}-\mathrm{K}$ ) in $\mathrm{NK}_{4} \mathrm{OH}$ (a clear picture taken from the QTAIM analysis, see detailed discussion below) compared to the $\mathrm{O}-\mathrm{K}$ and $\mathrm{F}-\mathrm{K}$ bonding interactions associated with the $\mathrm{OK}_{3} \mathrm{OH}$ and $\mathrm{FK}_{2} \mathrm{OH}$ species, respectively (two blue color discs in the ring bonds in both the moieties).

To attain some profound insights, such kinds of chemical bonding features were also corroborated by the QTAIM tool. As this technique provides a good understanding of the type, nature, and strength of bonding and nonbonding properties, hence, to assure such kinds of characteristics, the QTAIM method has been employed. The sign of the Laplacian of the ED $\left(\nabla^{2} \rho\right)$ at the BCP appeared to show depleted or "closed shell" (ionic and $\mathrm{vdW}$ ) interactions for the $\mathrm{O}-\mathrm{K}$ and $\mathrm{N}-\mathrm{K}$ bonds (i.e., for ionic interaction, $\nabla^{2} \rho>0$ and $\rho$ is typically small in the order of $10^{-2}$ atomic unit (au) and $10^{-3}$ au for a vdW interaction) whereas "shared" (covalent) interaction for the $\mathrm{OH}$ bond, that is, $\nabla^{2} \rho<0$ and $\rho>0.1$ au (see Figure 2). ${ }^{49}$ For example, the QTAIM topological parameters $\left(\rho, \nabla^{2} \rho, V\right)$ for the $\mathrm{O}-\mathrm{K}$ and $\mathrm{N}-\mathrm{K}$ interactions probed in $\mathrm{NK}_{4} \mathrm{OH}$ are $(0.031,+0.162$, -0.031 ) and $(0.0219,+0.078,-0.017)$ (in au), respectively, which fulfill their ionic character $\left(\nabla^{2} \rho>0\right.$ and $\rho \sim$ order of $10^{-2}$ $\mathrm{au}$ ), where the $\mathrm{O}-\mathrm{K}$ ionic interaction is much stronger than the $\mathrm{N}-\mathrm{K}$ ionic interaction as expected. ${ }^{50}$ The above findings have also been highlighted by the QTAIM pictures of the $\mathrm{NK}_{4} \mathrm{OH}$ species in which the $\mathrm{O}-\mathrm{K}$ bonds are shown by a solid line (i.e., showing stronger interactions) and $\mathrm{N}-\mathrm{K}$ bonds are represented by dotted lines (i.e., showing weaker interactions with respect to the $\mathrm{O}-\mathrm{K}$ bond). In the $\mathrm{NK}_{4} \mathrm{OH}$, the $\mathrm{NK}_{4}{ }^{+}$moiety possesses a high positive natural charge $(0.991 \mathrm{e})$; in fact, the hydroxyl $(\mathrm{OH})$ group having a negative natural charge $(-0.991 \mathrm{e})$ merely interacts with the $\mathrm{NK}_{4}^{+}$moiety and thus show ionic interactions, which were also validated by the QTAIM-based $\rho$ and $\nabla^{2} \rho$ topological parameters. Similarly, the $\mathrm{OK}_{3}{ }^{+}(0.973 \mathrm{e})$ and $\mathrm{FK}_{2}{ }^{+}$ $(0.979 \mathrm{e})$ moieties (consisting of higher positive natural charges) interact only with the $\mathrm{OH}$ groups having higher negative natural charges of $-0.973 \mathrm{e}$ and $-0.979 \mathrm{e}$ and thus show an ionic character, which were also confirmed by the QTAIM-based parameters. Moreover, the $\left(\rho: 0.3596\right.$ au, $\nabla^{2} \rho:-2.22$ au, and $V$ : $-0.763 \mathrm{au}$ ) values of the $\mathrm{OH}$ bond involved in the $\mathrm{NK}_{4} \mathrm{OH}$ species are characteristic of its covalent nature where the $\rho$ value is in the order of $10^{-1}$ au $(\rho>0.1 \mathrm{au})$ and the $\nabla^{2} \rho$ value is less than zero $\left(\nabla^{2} \rho<0\right)$. This (covalent nature) is also true for all $\mathrm{OH}$ bonds existing in all the inspected moieties.

In sequence, the order of the natural charges on the $(\mathrm{O}, \mathrm{H})$ atoms of the $\mathrm{OH}$ groups of $\mathrm{XK}_{n+1} \mathrm{OH}$ is $\mathrm{KOH}(-1.413 \mathrm{e}, 0.428 \mathrm{e})$ $>\mathrm{FK}_{2} \mathrm{OH}(-1.402 \mathrm{e}, 0.423 \mathrm{e})>\mathrm{OK}_{3} \mathrm{OH}(-1.389 \mathrm{e}, 0.416 \mathrm{e})>$ $\mathrm{NK}_{4} \mathrm{OH}(-1.388 \mathrm{e}, 0.397 \mathrm{e})$ in which the charges on the $\mathrm{O}$ atom of the latter two $\left(\mathrm{OK}_{3} \mathrm{OH}\right.$ and $\left.\mathrm{NK}_{4} \mathrm{OH}\right)$ are quite close. Very interestingly, the $\mathrm{O}-\mathrm{H}$ frequency $(\nu)$ for the same species follows the trend as $\mathrm{KOH}\left(3961.4 \mathrm{~cm}^{-1}\right)>\mathrm{NK}_{4} \mathrm{OH}(3940$ $\left.\mathrm{cm}^{-1}\right)>\mathrm{FK}_{2} \mathrm{OH}\left(3934.4 \mathrm{~cm}^{-1}\right) \sim \mathrm{OK}_{3} \mathrm{OH}\left(3934 \mathrm{~cm}^{-1}\right)$, which is almost consistent with the QTAIM-based parameters $\left(\rho, \nabla^{2} \rho\right.$, $V)$ as $\mathrm{KOH}(0.3602,-2.331,-0.776)>\mathrm{NK}_{4} \mathrm{OH}(0.3596$, $-2.22,-0.763)>\mathrm{FK}_{2} \mathrm{OH}(0.3577,-2.277,-0.767)>\mathrm{OK}_{3} \mathrm{OH}$ $(0.3577,-2.266,-0.766)$ (in au). Moreover, as the QTAIManalyzed $\left(\rho, \nabla^{2} \rho, V\right)$ values are characteristic of bond strengthmeasuring parameters, the order of the strength of the ring $\mathrm{O}-\mathrm{K}$ bonds of the $\mathrm{XK}_{n+1} \mathrm{OH}$ including the $\mathrm{KOH}$ is $\mathrm{KOH}(0.0445$, $+0.275,-0.056)>\mathrm{NK}_{4} \mathrm{OH}(0.031,+1.612,-0.031)>\mathrm{FK}_{2} \mathrm{OH}$ $(0.0294,+0.15,-0.029)>\mathrm{OK}_{3} \mathrm{OH}(0.0278,+0.142,-0.027)$ (in au) showing ionic character $\left(\rho \sim\right.$ in the order of $10^{-2}$ au and $\left.\nabla^{2} \rho>0\right)$. Additionally, if we have a look into the $\mathrm{X}-\mathrm{K}$ bonding feature in the same set of the species, the strengths $\left(\rho, \nabla^{2} \rho, V\right)$ of the $\mathrm{X}-\mathrm{K}$ bonds follow the order $\mathrm{FK}_{2} \mathrm{OH}(\mathrm{F}-\mathrm{K}: 0.0326,+0.169$, $-0.035)>\mathrm{OK}_{3} \mathrm{OH}(\mathrm{O}-\mathrm{K}: 0.0322,+0.151,-0.032)>\mathrm{NK}_{4} \mathrm{OH}$ $(\mathrm{N}-\mathrm{K}: 0.0219,+0.078,-0.017)$ (in au), which are in accordance with the order of the natural charges $\left(Q_{K}\right)$ on the ring $\mathrm{K}$ atoms of $\mathrm{XK}_{n+1} \mathrm{OH}$ species $\left(\mathrm{FK}_{2} \mathrm{OH}\right.$ : 0.976e) > $\left(\mathrm{OK}_{3} \mathrm{OH}: 0.955 \mathrm{e}\right)>\left(\mathrm{NK}_{4} \mathrm{OH}: 0.903 \mathrm{e}\right)$, which are in the reverse order of the $\mathrm{X}-\mathrm{K}$ bond lengths of $\mathrm{FK}_{2} \mathrm{OH}(\mathrm{F}-\mathrm{K}: 2.396$ $\AA)<\mathrm{OK}_{3} \mathrm{OH}(\mathrm{O}-\mathrm{K}: 2.464 \AA)<\mathrm{NK}_{4} \mathrm{OH}(\mathrm{N}-\mathrm{K}: 2.788 \AA)$ as expected. A reciprocal trend of the natural charges $\left(Q_{X}\right)$ on the $\mathrm{X}$ atoms for the same moieties is $\mathrm{FK}_{2} \mathrm{OH}\left(Q_{\mathrm{F}}:-0.973 \mathrm{e}\right)<$ 
$\mathrm{OK}_{3} \mathrm{OH}\left(Q_{\mathrm{O}}:-1.89 \mathrm{e}\right)<\mathrm{NK}_{4} \mathrm{OH}\left(Q_{\mathrm{N}}:-3.675 \mathrm{e}\right)$ is hoped where the largest enhanced negative charge on the $\mathrm{N}$ atom of $\mathrm{NK}_{4} \mathrm{OH}$ is due to its connection with four electropositive $\mathrm{K}$ atoms (having a better electron-donating tendency). Also, the natural charges on the $\mathrm{O}$ and $\mathrm{F}$ atoms of the $\mathrm{OK}_{3} \mathrm{OH}\left(Q_{0}\right.$ : $-1.89 \mathrm{e})$ and $\mathrm{FK}_{2} \mathrm{OH}\left(Q_{\mathrm{F}}:-0.973 \mathrm{e}\right)$ species are successively in a decreasing order, which are linked with three and two $\mathrm{K}$ atoms, respectively. It is appealing to note that the bond lengths of the hydroxyl group $(\mathrm{O}-\mathrm{H})$ for all four K-related species range from 0.957 to $0.959 \AA$ (see Figure 2). In addition, there is good resemblance between the optimized structures of all SAHs $\left(\mathrm{XK}_{n+1} \mathrm{OH}\right)$ (Figure 2) and their respective superalkalis (Figure 1).

$\mathrm{NaOH}$ and $\mathrm{XNa}_{n+1} \mathrm{OH}$ Species. Now proceeding from Krelated species toward the Na-related moieties, in the case of an optimized linear $\mathrm{NaOH}$ fundamental base (see Figure 3), the $\mathrm{Na}-\mathrm{O}$ and $\mathrm{O}-\mathrm{H}$ bond lengths have been determined as 1.98 and $0.954 \AA$, respectively, whose values are close to the experimental values ( $\mathrm{Na}-\mathrm{O}: 1.95 \AA$ and $\mathrm{O}-\mathrm{H}: 0.941 \AA) .{ }^{51}$ As discussed above about the structural information of the $\mathrm{XK}_{n+1} \mathrm{OH}$-related bases, the optimized $\mathrm{XNa}_{n+1} \mathrm{OH}$ set of bases also has similar geometrical features (in terms of symmetry and geometry).

Figure 3 shows that the bond lengths in the $\mathrm{XNa}_{n+1} \mathrm{OH}$ bases such as $\mathrm{X}-\mathrm{Na}\left(\mathrm{F}-\mathrm{Na}\right.$ in $\mathrm{FNa}_{2} \mathrm{OH}: 2.157 \AA, \mathrm{O}-\mathrm{Na}$ in $\mathrm{ONa}_{3} \mathrm{OH}: 2.178 \AA$, and $\mathrm{N}-\mathrm{Na}$ in $\mathrm{NNa}_{4} \mathrm{OH}: 2.328 \AA$ ) were detected to be larger than those in the corresponding superalkalis $\left(\mathrm{F}-\mathrm{Na}\right.$ in $\mathrm{FNa}_{2}: 2.114 \AA$, O-Na in $\mathrm{ONa}_{3}: 2.096$ $\AA$, and $\mathrm{N}-\mathrm{Na}$ in $\mathrm{NNa}_{4}: 2.173 \AA$ ) and also in the $\mathrm{NaOH}$ base (O-Na: $1.98 \AA$ ). Such findings are due to the CT taking place from the alkali metal ( $\mathrm{Na}$ atoms) to the $\mathrm{OH}$ group as well as the ring electronegative $(\mathrm{F}, \mathrm{O}$, and $\mathrm{N})$ atoms. In addition, a decreasing trend of the natural charges $\left(Q_{\mathrm{Na}}\right)$ on the $\mathrm{Na}$ atoms (with an approximate $0.02 \mathrm{e}$ difference) in the $\mathrm{NaOH}(0.984 \mathrm{e})$, $\mathrm{FNa}_{2} \mathrm{OH}(0.967 \mathrm{e}), \mathrm{ONa}_{3} \mathrm{OH}(0.947 \mathrm{e})$, and $\mathrm{NNa}_{4} \mathrm{OH}(0.927 \mathrm{e})$ can be seen, which is expected evidently because of increased $\mathrm{X}-\mathrm{Na}$ bond lengths (including the $\mathrm{O}-\mathrm{Na}$ bond length of $\mathrm{NaOH}$ ) proceeding from the $\mathrm{NaOH}$ alkali hydroxide to its SAHs (i.e., $\mathrm{NaOH}(1.98 \AA)<\mathrm{FNa}_{2} \mathrm{OH}(\mathrm{F}-\mathrm{Na}: 2.157 \AA)<$ $\mathrm{ONa}_{3} \mathrm{OH}(\mathrm{O}-\mathrm{Na}: 2.178 \AA)<\mathrm{NNa}_{4} \mathrm{OH}(\mathrm{N}-\mathrm{Na}: 2.328 \AA)$ ). One-to-one structural similarity between the equilibrium structures of the $\mathrm{XNa}_{n+1} \mathrm{OH} \mathrm{SAHs}$ (Figure 3) and $\mathrm{XNa}_{n+1}$ superalkalis (Figure 1) can also be seen.

Now, having a closer look into the NCI-based 2D scatter plots and 3D isosurface maps of the $\mathrm{XNa}_{n+1} \mathrm{OH}$ species, such graphic visualizations give a similar pattern like that for the abovediscussed $\mathrm{XK}_{n+1} \mathrm{OH}$-related species, and especially, the $\mathrm{N}-\mathrm{Na}$ ring bonds (greenish-blue color discs) involved in the $\mathrm{NNa}_{4} \mathrm{OH}$ base show stronger interactions than the $\mathrm{N}-\mathrm{K}$ ring bonds (dark green color discs) present in the $\mathrm{NK}_{4} \mathrm{OH}$ moiety. One can see that the extremely weak vdW interactions (green color spikes in the $2 \mathrm{D}$ scatter plots ranging between 0 and -0.01 au as shown in Figure 3) in the $\mathrm{XNa}_{n+1} \mathrm{OH}$-related bases are also validated by their corresponding 3D isosurfaces (see the small lentils at the center of the rings). The QTAIM bond strength-measuring indices $\left(\rho, \nabla^{2} \rho, V\right)$ also confirm that the $\mathrm{N}-\mathrm{Na}$ bonds of the $\mathrm{NNa}_{4} \mathrm{OH}$ have higher $(0.0227,+0.138$, and $-0.024 \mathrm{au})$ values (i.e., showing stronger metal-nonmetal ionic bonding) than the $(0.0219,+0.078$, and $-0.017 \mathrm{au})$ values of the $\mathrm{N}-\mathrm{K}$ bonds of the $\mathrm{NK}_{4} \mathrm{OH}$ SAH; however, such $\mathrm{N}-\mathrm{K}$ bonds are much weaker than those of $\mathrm{F}-\mathrm{Na}(0.0279,+0.2,-0.0363 \mathrm{au})$ and $\mathrm{O}-\mathrm{Na}(0.0308$, $+0.207,-0.037 \mathrm{au})$ of the same system. In order to examine the $\mathrm{X}-\mathrm{Na}(\mathrm{F}-\mathrm{Na}, \mathrm{O}-\mathrm{Na}$, and $\mathrm{N}-\mathrm{Na})$ bonding features present in the $\mathrm{XNa}_{n+1} \mathrm{OH}$ species, the bond strength-quantifying parameters $\left(\rho, \nabla^{2} \rho\right)$ show ionic behavior, which is also supported by their respective local potential energy densities $(V)$; $\left(V_{\mathrm{O}-\mathrm{Na}}\right.$ : $-0.037 \mathrm{au}),\left(V_{\mathrm{F}-\mathrm{Na}}:-0.036 \mathrm{au}\right)$, and $\left(V_{\mathrm{N}-\mathrm{Na}}:-0.024 \mathrm{au}\right)$, respectively.

The $\left(\rho, \nabla^{2} \rho, V\right)$ values for the $\mathrm{O}-\mathrm{Na}$ bonds of the $\mathrm{NaOH}$, $\mathrm{FNa}_{2} \mathrm{OH}, \mathrm{ONa}_{3} \mathrm{OH}$, and $\mathrm{NNa}_{4} \mathrm{OH}$ species are $(0.0431,+0.38$, -0.067), (0.0296, +0.216, -0.0364), (0.0282, +0.204, -0.034), and $(0.0294,+0.214,-0.036)$, respectively, showing ionic character, which follow the QTAIM-based ionic criteria $(\rho \sim$ in the order of $10^{-2}$ au and $\left.\nabla^{2} \rho>0\right)$. By extracting information about the $\mathrm{O}-\mathrm{Na}$ nonmetal-metal bonding interactions, another nonmetal-metal $(\mathrm{X}-\mathrm{Na})$ bonding interactions in all the $\mathrm{Na}$ related species have also been examined by the QTAIM topological parameters, and here, for example, the $\left(\rho, \nabla^{2} \rho\right)$ values (in au) of the $\mathrm{N}-\mathrm{Na}(0.0227,+0.138)$ bonds in the $\mathrm{NNa}_{4} \mathrm{OH}$ system also appear to be thecharacteristic of ionic character ( $\rho$ value is in the order of 10-2 au and $\left.\nabla^{2} \rho>0\right)$ having the $V$ value as -0.024 au where the $\mathrm{O}-\mathrm{Na}$ bonds (indicated by black solid lines) are much stronger than those of the $\mathrm{N}-\mathrm{Na}$ bond(s) (shown by black dotted lines). ${ }^{50}$ This is because of the stronger attractive interaction occurring between the $\mathrm{O}$ and $\mathrm{Na}$ atoms in the $\mathrm{O}-\mathrm{Na}$ bonds as compared to those between the $\mathrm{N}$ and $\mathrm{Na}$ atoms in the $\mathrm{N}-\mathrm{Na}$ bonds. A noteworthy observation ( $\mathrm{O}-\mathrm{Na}$ versus $\mathrm{X}-\mathrm{K}$ bonding interactions) can be corroborated from the $\mathrm{FNa}_{2} \mathrm{OH}$ (the $\mathrm{O}-\mathrm{Na}$ bond (coupled with an $\mathrm{OH}$ covalent bond) is stronger than the $\mathrm{F}-\mathrm{Na}$ bond) and $\mathrm{ONa}_{3} \mathrm{OH}$ (the $\mathrm{O}-\mathrm{Na}$ bond (linked to the $\mathrm{OH}$ covalent bond) is weaker than the $\mathrm{O}-\mathrm{Na}$ bond) species (see Figure 3) in which an opposite trend can be seen which could be due to the electronegativity difference as well as the number of electropositive $\mathrm{Na}$ atoms taking part therein. Moreover, the QTAIM parameters $\left(\rho, \nabla^{2} \rho, V\right)$ (in au) for the $\mathrm{OH}$ bonds of the $\mathrm{Na}$ related species range from $(0.358,-2.319,-0.772)$ to $(0.3626$, $-2.384,-0.788)$ showing covalent character $(\rho>0.1$ au and $\left.\nabla^{2} \rho<0\right)$. The higher natural charges on $\mathrm{XNa}_{n+1}{ }^{+}$and their associated $\mathrm{OH}$ groups of the $\mathrm{XK}_{n+1} \mathrm{OH}$ species demonstrate that the $\mathrm{FNa}_{2}{ }^{+}, \mathrm{ONa}_{3}{ }^{+}$, and $\mathrm{NNa}_{4}{ }^{+}$moieties having positive natural charges as $0.967 \mathrm{e}, 0.947 \mathrm{e}$, and $0.927 \mathrm{e}$, respectively, interact only with the corresponding $\mathrm{OH}$ groups consisting of opposite negative natural charges as $-0.967 \mathrm{e},-0.947 \mathrm{e},-0.927 \mathrm{e}$ and confirm the existence of ionic interactions, which is also assured by the QTAIM tool.

Using the NBO approach, the trend of the natural charges (Q) on the $(\mathrm{O}, \mathrm{H})$ atoms for the Na-related species has been computed as $\mathrm{NaOH}(-1.419 \mathrm{e}, 0.436 \mathrm{e})>\mathrm{FNa}_{2} \mathrm{OH}(-1.403 \mathrm{e}$, $0.435 \mathrm{e})>\mathrm{ONa}_{3} \mathrm{OH}(-1.383 \mathrm{e}, 0.428 \mathrm{e})>\mathrm{NNa}_{4} \mathrm{OH}(-1.369 \mathrm{e}$, $0.425 \mathrm{e})$ where the charge on the $\mathrm{H}$ atoms of $\mathrm{NaOH}$ and $\mathrm{FNa}_{2} \mathrm{OH}$ is approximately the same. Moreover, the Na-series systems consisting of higher $\mathrm{O}-\mathrm{H}$ stretching frequencies as $\mathrm{NaOH}\left(4012.5 \mathrm{~cm}^{-1}\right)>\mathrm{FNa}_{2} \mathrm{OH}\left(3969.8 \mathrm{~cm}^{-1}\right)>\mathrm{ONa}_{3} \mathrm{OH}$ $\left(3967 \mathrm{~cm}^{-1}\right)>\mathrm{NNa}_{4} \mathrm{OH}\left(3958 \mathrm{~cm}^{-1}\right)$ as compared to the corresponding set of the $\mathrm{K}$-series bases, and here, the frequencies $(\nu)$ trend of the $\mathrm{O}-\mathrm{H}$ covalent bonds for the $\mathrm{XNa}_{n+1} \mathrm{OH}$ species (including the $\mathrm{NaOH}$ base) are slightly from that of the $\mathrm{K}$ related species. The force constants of the respective bonds in the Na-related SAHs also vary as $\mathrm{F}-\mathrm{Na}>\mathrm{O}-\mathrm{Na}>\mathrm{N}-\mathrm{Na}$. The negative charge on the $\mathrm{F}$ atom $\left(Q_{\mathrm{F}}:-0.967 \mathrm{e}\right)$ of $\mathrm{FNa}_{2} \mathrm{OH}$ is observed to be the smallest because of its bonding with only two electropositive $\mathrm{Na}$ atoms; however, in the case of $\mathrm{ONa}_{3} \mathrm{OH}$ and $\mathrm{NNa}_{4} \mathrm{OH}$, the largest negative natural charges on the $\mathrm{O}\left(Q_{\mathrm{O}}\right.$ : $-1.903 \mathrm{e})$ and $\mathrm{N}\left(Q_{\mathrm{N}}:-2.55 \mathrm{e}\right)$ atoms are analyzed, which could be due to their connection with three and four electropositive 
$\mathrm{Na}$ atoms, respectively. The $\mathrm{O}-\mathrm{H}$ stretching frequency findings come up with the same order of the some important and selected QTAIM wavefunction-based parameters $\left(\rho, \nabla^{2} \rho, V\right)$ as $\mathrm{NaOH}$ $(0.3626,-2.384,-0.788)>\mathrm{FNa}_{2} \mathrm{OH}(0.3596,-2.34,-0.777)$ $>\mathrm{ONa}_{3} \mathrm{OH}(0.3595,-2.326,-0.775)>\mathrm{NNa}_{4} \mathrm{OH}(0.358$, $-2.319,-0.772$ ) (in au), which shows their covalent character and this feature is assisted by the QTAIM-based covalent criteria $\left(\rho>0.1\right.$ au and $\left.\nabla^{2} \rho<0\right)$. It is also interesting to observe that the natural charges on the $\mathrm{OH}$-related $\mathrm{O}$ atom of the $\mathrm{ONa}_{3} \mathrm{OH}$ $(-1.383 \mathrm{e})$ and $\mathrm{NNa}_{4} \mathrm{OH}(-1.369 \mathrm{e})$ have been computed to be smaller than those of the $\mathrm{OK}_{3} \mathrm{OH}(-1.389 \mathrm{e})$ and $\mathrm{NK}_{4} \mathrm{OH}$ $(-1.388)$ species, which could be because of higher number of $\mathrm{K}$ atoms enagaged therein (latter two species); however, an opposite trend can be seen in the case of the $\mathrm{H}$ atoms taking part therein $\left(\mathrm{ONa}_{3} \mathrm{OH}(0.428 \mathrm{e})=\mathrm{KOH}(0.428 \mathrm{e})>\mathrm{OK}_{3} \mathrm{OH}\right.$ $(0.416 \mathrm{e})$ and $\mathrm{NNa}_{4} \mathrm{OH}(0.425 \mathrm{e}) \sim \mathrm{FK}_{2} \mathrm{OH}(0.423 \mathrm{e})>\mathrm{NK}_{4} \mathrm{OH}$ $(0.397 \mathrm{e}))$.

$\mathrm{LiOH}$ and $\mathrm{XLi}_{n+1} \mathrm{OH}$ Species. As discussed above regarding the $\mathrm{Na}$ - and $\mathrm{K}$-based SAHs, having a quick look into the $\mathrm{Li}$ related systems (i.e., mainly the NCI plot and QTAIM analysis have been emphasized here), glimpses on the Li-related systems is provided in this section. The bond lengths ( $\mathrm{Li}-\mathrm{O}: 1.607 \AA$ and $\mathrm{O}-\mathrm{H}: 0.952 \AA$ ) of the optimized linear $\mathrm{LiOH}$ base (see Figure 4) are close to the experimental values ( $\mathrm{Li}-\mathrm{O}: 1.582 \AA$ and $\mathrm{O}-\mathrm{H}: 0.969 \AA) .{ }^{52}$ The X-Li bond lengths of the $\mathrm{XLi}_{n+1} \mathrm{OH}$ SAHs are larger than those of the corresponding Li-based superalkalis $\left(\mathrm{XLi}_{n+1}: \mathrm{FLi}_{2}, \mathrm{OLi}_{3}\right.$, and $\left.\mathrm{NLi}_{4}\right)$ and also the $\mathrm{LiOH}$ base. Such alterations seem to be due to the $\mathrm{CT}$ process from the engaged $\mathrm{Li}$ atoms to the $\mathrm{OH}$ group and also to the other electronegative monovalent $(\mathrm{F})$, divalent $(\mathrm{O})$, and trivalent $(\mathrm{N})$ atoms taking part therein. The NCI plots and QTAIM pictures displayed in Figure 4 show that the bonds associated in the $\mathrm{LiOH}$ and $\mathrm{XLi}_{n+1} \mathrm{OH}$ are stronger than the corresponding bonds involved in both the above discussed $\mathrm{XNa}_{n+1} \mathrm{OH}$ as well as $\mathrm{XK}_{n+1} \mathrm{OH}$ species.

The NCI-based 2D scatter plots of the Li-associated SAHs clearly illustrate that the blue colored spikes are close to -0.04 showing stronger bonding interactions compared to those in the $\mathrm{K}$ - and Na-related fundamental bases and allied SAHs including the $\mathrm{LiOH}$ having a blue peak beyond -0.05 whereas in the $\mathrm{KOH}$ and $\mathrm{NaOH}$ bases, peaks are in between -0.04 and -0.05 . The $\mathrm{NCI} 3 \mathrm{D}$ isosurfaces (blue color lentils lying between the $\mathrm{O}-\mathrm{Li}$ and $\mathrm{X}-\mathrm{Li}$ ring bonds) also exemplify and authenticate the $2 \mathrm{D}$ scatter plots. Stronger vdW interactions with respect to the $\mathrm{XK}_{n+1} \mathrm{OH}$ and $\mathrm{XNa}_{n+1} \mathrm{OH}$ species can be seen in Figure 4 (2D scatter plots and 3D isosurface maps), which may further be corroborated by both the $2 \mathrm{D}$ scatter plots (i.e., spikes lying between -0.01 and -0.02 ) and 3D isosurface maps (green color lentils located inside the ring). Moreover, such above-highlighted vdW interactions (i.e., see the diagonal connection: $\mathrm{O} \cdots$ $\left.\mathrm{F} @ \mathrm{FLi}_{2} \mathrm{OH}\right), \mathrm{O} \cdots \mathrm{O} @ \mathrm{OLi}_{3} \mathrm{OH}$, and $\mathrm{O} \cdots \mathrm{N} @ \mathrm{NLi}_{4} \mathrm{OH}$ shown in the pink and black dotted colors in the $3 \mathrm{D}$ isosurface maps and QTAIM pictures, respectively) seen in the $\mathrm{XLi}_{n+1} \mathrm{OH}$ species appear to provide extra stability to all the ring-associated moieties, which could be due to their dominating close contacts diagonally and thus demonstrating more attractive interactions compared to other two sets of the SAHs, $\mathrm{XK}_{n+1} \mathrm{OH}$ and $\mathrm{XNa}_{n+1} \mathrm{OH}$. In terms of some bond strength-quantifying parameters $\left(\rho, \nabla^{2} \rho, V\right)$, for all the $\mathrm{XLi}_{n+1} \mathrm{OH}$ SAHs, the order of the bond strengths of diagonally connected atoms is $\mathrm{O} \cdots \mathrm{F}$ $(0.0188,+0.059,-0.018)>\mathrm{O} \cdots \mathrm{O}(0.0175,+0.049,-0.016)>$ $\mathrm{O} \cdots \mathrm{N}(0.016,+0.039,-0.014)$ (in au), which reveals to be dependent on the number of extra Li atoms (excluding the ring/ bridged $\mathrm{Li}$ atoms) involved in the species because the presence of extra terminal $\mathrm{Li}$ atom enhances the negative charge on the $\mathrm{X}$ atom, which may be responsible for more repulsion with the diagonally connected $\mathrm{O}$ atom present on opposite side.

In order to probe the order of the bond strength of the $\mathrm{OH}$ associated $\mathrm{O}-\mathrm{Li}$ bonding interactions, a pattern like $\mathrm{LiOH}$ $(0.0635,+0.635,-0.115)>\mathrm{FLi}_{2} \mathrm{OH}(0.0407,+0.339,-0.057)$ $>\mathrm{OLi}_{3} \mathrm{OH}(0.0388,+0.322,-0.054)>\mathrm{NLi}_{4} \mathrm{OH}(0.0387$, $+0.318,-0.053$ ) (in au) has been observed in all four Li-related moieties acquired from the QTAIM-based $\left(\rho, \nabla^{2} \rho, V\right)$ parameters having much larger values (i.e., stronger) than the $\mathrm{OH}$-coupled $\mathrm{O}-\mathrm{M}(\mathrm{O}-\mathrm{K}$ and $\mathrm{O}-\mathrm{Na})$ bonds of the $\mathrm{XM}_{n+1} \mathrm{OH}$ species, and also the $\mathrm{OH}$-connected $\mathrm{O}-\mathrm{Li}$ bonds show stronger ionic character $\left(\rho \sim\right.$ in the order of $10^{-2}$ au and $\left.\nabla^{2} \rho>0\right)$ than the $\mathrm{O}-\mathrm{K}$ and $\mathrm{O}-\mathrm{Na}$ bonds. The above trend is opposite to their respective $\mathrm{O}-\mathrm{Li}$ bond lengths as $\mathrm{LiOH}(1.607 \AA)<\mathrm{FLi}_{2} \mathrm{OH}$ $(1.796 \AA)<\mathrm{OLi}_{3} \mathrm{OH}(1.81 \AA)<\mathrm{NLi}_{4} \mathrm{OH}(1.812 \AA)$ as expected . Like the $\mathrm{XNa}_{n+1} \mathrm{OH}$ species, the order of the $\mathrm{X}-\mathrm{Li}(\mathrm{X}=\mathrm{F}, \mathrm{O}$, and $\mathrm{N}$ ) bond strength of the $\mathrm{XLi}_{n+1} \mathrm{OH}$ SAHs obtained from the $\left(\rho, \nabla^{2} \rho, V\right)$ parameters is $\left(\mathrm{OLi}_{3} \mathrm{OH}(\mathrm{O}-\mathrm{Li}: 0.0443,+0.344\right.$, $-0.062)) \geq\left(\mathrm{FLi}_{2} \mathrm{OH}(\mathrm{F}-\mathrm{Li}: 0.0426,+0.36,-0.061)\right)>$ $\left(\mathrm{NLi}_{4} \mathrm{OH}(\mathrm{N}-\mathrm{Li}: 0.0361,+0.239,-0.045)\right.$ ) (in au); however, their corresponding bond lengths are $\mathrm{O}-\mathrm{Li}(1.796 \AA), \mathrm{F}-\mathrm{Li}$ (1.752 $\AA$ ), and $\mathrm{N}-\mathrm{Li}(1.917 \AA)$, which shows that such properties do not depend only on the bond lengths but also on the natural charges on the constituents. The analyzed natural charges on the bridged $\mathrm{Li}$ atoms of the $\mathrm{XLi}_{n+1} \mathrm{OH}\left(\mathrm{FLi}_{2} \mathrm{OH}\right.$, $\mathrm{OLi}_{3} \mathrm{OH}$, and $\left.\mathrm{NLi}_{4} \mathrm{OH}\right)$ are $0.91 \mathrm{e}, 0.871 \mathrm{e}$, and $0.817 \mathrm{e}$, respectively, along with the $\mathrm{LiOH}$ having the highest natural charge $\left(\mathrm{Q}_{\mathrm{Li}}\right)$ on the $\mathrm{Li}$ atom as $0.96 \mathrm{e}$. Such a consequence is possible due to the increased bond lengths from the $\mathrm{LiOH}$ base to the $\mathrm{NLi}_{4} \mathrm{OH} \mathrm{SAH}$. In addition, having a view into the $\mathrm{O}-\mathrm{H}$ stretching frequency of the $\mathrm{XLi}_{n+1} \mathrm{OH}$ species, a trend as $\mathrm{LiOH}$ $\left(4049.8 \mathrm{~cm}^{-1}\right)>\mathrm{FLi}_{2} \mathrm{OH}\left(4016.8 \mathrm{~cm}^{-1}\right)>\mathrm{OLi}_{3} \mathrm{OH}(4009.2$ $\left.\mathrm{cm}^{-1}\right)>\mathrm{NLi}_{4} \mathrm{OH}\left(3996 \mathrm{~cm}^{-1}\right)$ can be seen, which is in close proximity to the order of the QTAIM-analyzed $\left(\rho, \nabla^{2} \rho, V\right)$ parameters as $\mathrm{LiOH}(0.3647,-2.472,-0.799)>\mathrm{FLi}_{2} \mathrm{OH}$ $(0.3621,-2.432,-0.79)>\mathrm{OLi}_{3} \mathrm{OH}(0.3618,-2.409,-0.788)$ $>\mathrm{NLi}_{4} \mathrm{OH}(0.3606,-2.392,-0.784)$ (in au). This pattern is considered with the alteration in their analyzed respective $\mathrm{O}-\mathrm{H}$ bond lengths $\mathrm{LiOH}(0.952 \AA)<\mathrm{FLi}_{2} \mathrm{OH}(0.954 \AA)=\mathrm{OLi}_{3} \mathrm{OH}$ $(0.954 \AA)<\mathrm{NLi}_{4} \mathrm{OH}(0.955 \AA)$. Moreover, the bond lengths of the $\mathrm{OH}$ group of the $\mathrm{XLi}_{n+1} \mathrm{OH}$ superbases ranging from 0.952 to $0.955 \AA$ (see Figure 4) show a marginal change (0.003 $\AA$ ).

Dissociation Energy ( $\Delta E$ and $\left.D_{\mathrm{e}}\right)$. As highlighted above, using the $\mathrm{NBO}$ approach, the interaction (i.e., type and nature) between the superalkalis $\left(\mathrm{XM}_{n+1}\right)$ and hydroxyl groups $(-\mathrm{OH})$ has been detected to be ionic as in the $\mathrm{KOH}$ and $\mathrm{NaOH}$ along with the $\mathrm{LiOH}$, which have been examined by looking into the segregations of the $\mathrm{XM}_{n+1} \mathrm{OH}$ into the superalkali cations $\left(\mathrm{XM}_{n+1}{ }^{+}\right)$and $\mathrm{OH}^{-}$and then the reactions have been compared with those of the $\mathrm{KOH}, \mathrm{NaOH}$, and $\mathrm{LiOH}$. From Table 2, it is interesting to see that the ionic detachment/dissociation energies $(\Delta E)$ of all the $\mathrm{XM}_{n+1} \mathrm{OH}$ have been calculated to be smaller than those of their corresponding basic hydroxides $(\mathrm{KOH}, \mathrm{NaOH}$, and $\mathrm{LiOH})$. For instance, the order of $\Delta E$ values (in $\mathrm{kJ} / \mathrm{mol}$ ) for the K-based SAHs is $\mathrm{KOH}(589)>\mathrm{FK}_{2} \mathrm{OH}$ (567.9) $>\mathrm{NK}_{4} \mathrm{OH}(554.7)>\mathrm{OK}_{3} \mathrm{OH}$ (516). A similar trend can be seen in the case of Na-related species as $\mathrm{NaOH}(649.2)>$ $\mathrm{FNa}_{2} \mathrm{OH}(645.1)>\mathrm{NNa}_{4} \mathrm{OH}(594)>\mathrm{ONa}_{3} \mathrm{OH}$ (546.4) (in kJ/ $\mathrm{mol})$. Moreover, a slightly different pattern for the Li-related species can be viewed as $\mathrm{LiOH}(787.4)>\mathrm{FLi}_{2} \mathrm{OH}(766.3)>$ $\mathrm{OLi}_{3} \mathrm{OH}(695)>\mathrm{NLi}_{4} \mathrm{OH}$ (662) (in $\mathrm{kJ} / \mathrm{mol}$ ). Such trends are 
Table 2. Absolute PA, Intrinsic GB, and Dissociation Energies $\left(\Delta E\right.$ and $\left.D_{e}\right)$ of the $\mathrm{KOH}, \mathrm{NaOH}$, and $\mathrm{LiOH}$ and $\mathrm{XM}_{n+1} \mathrm{OH}$ Species $\left(\mathrm{XM}_{n+1}=\mathrm{FK}_{2}, \mathrm{OK}_{3}, \mathrm{NK}_{4}, \mathrm{FNa}_{2}, \mathrm{ONa}_{3}\right.$, $\mathrm{NNa}_{4}, \mathrm{FLi}_{2}, \mathrm{OLi}_{3}$, and $\left.\mathrm{NLi}_{4}\right)^{a}$

\begin{tabular}{|c|c|c|c|c|c|}
\hline species & symmetry & PA & GB & $\Delta E$ & $D_{\mathrm{e}}$ \\
\hline $\mathrm{KOH}$ & $\mathrm{C}_{\infty \mathrm{v}}$ & $\begin{array}{l}1129.2 \\
(1101.8)^{d}\end{array}$ & $\begin{array}{l}1104.8 \\
(1075.4)^{d}\end{array}$ & 589 & - \\
\hline $\begin{array}{l}\mathrm{FK}_{2} \mathrm{OH} \\
\quad(\text { linear })^{b}\end{array}$ & $\mathrm{C}_{1}$ & 1126.9 & 1114.3 & 567.9 & 203.2 \\
\hline $\begin{array}{c}\mathrm{FK}_{2} \mathrm{OH} \\
(\text { ring })^{c}\end{array}$ & $\mathrm{C}_{2 \mathrm{v}}$ & 1103 & 1077.9 & - & - \\
\hline $\mathrm{OK}_{3} \mathrm{OH}$ & $\mathrm{C}_{2 \mathrm{v}}$ & 1168.4 & 1146.9 & 516 & 197.1 \\
\hline $\mathrm{NK}_{4} \mathrm{OH}$ & $\mathrm{C}_{2 \mathrm{v}}$ & 1134.7 & 1117.2 & 554.7 & 164.6 \\
\hline $\mathrm{NaOH}$ & $\mathrm{C}_{\infty \mathrm{v}}$ & $\begin{array}{l}1092.6 \\
(1071.8)^{d}\end{array}$ & $\begin{array}{l}1066.4 \\
(1044.8)^{d}\end{array}$ & 649.2 & \\
\hline $\begin{array}{l}\mathrm{FNa}_{2} \mathrm{OH} \\
\quad(\text { linear })^{b}\end{array}$ & $\mathrm{C}_{1}$ & 1073.5 & 1056.5 & 645.1 & 244.6 \\
\hline$\underset{\text { (ring) }^{c}}{\mathrm{FNa}_{2} \mathrm{OH}}$ & $\mathrm{C}_{2 \mathrm{v}}$ & 1034.1 & 1008.4 & - & - \\
\hline $\mathrm{ONa}_{3} \mathrm{OH}$ & $\mathrm{C}_{2 \mathrm{v}}$ & 1106.2 & 1081.5 & 546.4 & 246.2 \\
\hline $\mathrm{NNa}_{4} \mathrm{OH}$ & $\mathrm{C}_{2 \mathrm{v}}$ & 1094.9 & 1079.8 & 594 & 220.7 \\
\hline $\mathrm{LiOH}$ & $\mathrm{C}_{\infty \mathrm{v}}$ & $\begin{array}{l}1001.3 \\
(1000.1)^{d}\end{array}$ & $\begin{array}{l}975.9 \\
\quad(972.1)^{d}\end{array}$ & 787.4 & \\
\hline $\begin{array}{l}\mathrm{FLi}_{2} \mathrm{OH} \\
\quad(\text { linear })^{b}\end{array}$ & $\mathrm{C}_{1}$ & 990.3 & 972.4 & 766.3 & 260.5 \\
\hline $\begin{array}{l}\mathrm{FLi}_{2} \mathrm{OH} \\
\text { (ring) }\end{array}$ & $\mathrm{C}_{2 \mathrm{v}}$ & 939.8 & 912.3 & - & - \\
\hline $\mathrm{OLi}_{3} \mathrm{OH}$ & $\mathrm{C}_{2 \mathrm{v}}$ & 1027.4 & 1001.7 & 695 & 269.1 \\
\hline $\mathrm{NLi}_{4} \mathrm{OH}$ & $\mathrm{C}_{2 \mathrm{v}}$ & 1047.7 & 1021.5 & 662 & 254.4 \\
\hline
\end{tabular}

${ }^{a} \mathbf{P A}, \mathbf{G B}$, and dissociation energies $\left(\Delta E\right.$ and $\left.D_{\mathrm{e}}\right)$ are in $\mathrm{kJ} / \mathrm{mol}$ and the $E_{\text {gap }}$ values are in $\mathrm{eV} .{ }^{b}\left(\mathrm{XM}_{n+1} \mathrm{OH}\right)_{\text {ring }}+\left(\mathrm{H}^{+}\right)-$ $\left(\mathrm{XM}_{n+1} \mathrm{OH}_{2}^{+}\right)_{\text {linear }}$ has been used for the PA and $\mathbf{G B}$ calculations. ${ }^{c}\left(\mathrm{XM}_{n+1} \mathrm{OH}\right)_{\text {ring }}+\left(\mathrm{H}^{+}\right)-\left(\mathrm{XM}_{n+1} \mathrm{OH}_{2}^{+}\right)_{\text {ring }}$ has been used for the PA and GB calculations. ${ }^{d}$ These data are sorted according to the empirical formula as well as according to the evaluated gas basicity. ${ }^{21}$

very close to the $\mathrm{XM}_{n+1}$ superalkalis having smaller IPs as compared to those of the corresponding $\mathrm{K}, \mathrm{Na}$, and $\mathrm{Li}$ alkali metal atoms (see Table 1). For example, in the case of K-related species, the IP values of $\mathrm{XM}_{n+1}\left(\mathrm{FK}_{2}: 2.934 \mathrm{eV}, \mathrm{OK}_{3}: 2.707 \mathrm{eV}\right.$, $\left.\mathrm{NK}_{4}: 1.368 \mathrm{eV}\right)$ are much lower than that of the $\mathrm{K}$ having an IP value of $4.235 \mathrm{eV}$.

It should be noted that the IP value of the K-related species has been determined to be smaller than those of $\mathrm{Na}$ - and $\mathrm{Li}$ related species. By probing the existence of the $\mathrm{XM}_{n+1} \mathrm{OH}$ species at least in the gas phase, fragmentation into stable molecules (namely, $\mathrm{FK}_{2} \mathrm{OH} \rightarrow \mathrm{KOH}+\mathrm{KF}$; $\mathrm{OK}_{3} \mathrm{OH} \rightarrow \mathrm{KOH}+$ $\mathrm{K}_{2} \mathrm{O}$; and $\mathrm{NK}_{4} \mathrm{OH} \rightarrow \mathrm{KOH}+\mathrm{K}_{3} \mathrm{~N}$ ) has been contemplated. The analyzed detachment/dissociation energies $\left(D_{\mathrm{e}}\right)$ have been found to be greater than zero (see Table 2) where the order of the $D_{\mathrm{e}}$ values for K-related moieties has been found to be $\mathrm{NK}_{4} \mathrm{OH}(164.6)<\mathrm{OK}_{3} \mathrm{OH}(197.1)<\mathrm{FK}_{2} \mathrm{OH}$ (203.2) (in kJ/ mol) except in the case of Na-related $\left(\mathrm{NNa}_{4} \mathrm{OH}(220.7)<\right.$ $\left.\mathrm{FNa}_{2} \mathrm{OH}(244.6)<\mathrm{ONa}_{3} \mathrm{OH}(246.2)\right)$ and Li-related $\left(\mathrm{NLi}_{4} \mathrm{OH}\right.$ $\left.(254.4)<\mathrm{FLi}_{2} \mathrm{OH}(260.5)<\mathrm{OLi}_{3} \mathrm{OH}(269.1)\right)($ in $\mathrm{kJ} / \mathrm{mol})$ systems showing slightyl different patterns. The outcomes based on the abovementioned reaction procedure (fragmentation analyses) infer that synthesis of novel species like $\mathrm{XM}_{n+1} \mathrm{OH}$ can be realized energetically possible at least in the gas phase if the $\mathrm{XM}_{n+1}$ moieties are used.

Protonated Superalkali Hydroxide (PSAH) Species $\left(\mathrm{XM}_{n+1} \mathrm{OH}_{2}^{+}\right)$and Their Absolute PA and GB. Figure 5 shows the optimized (equilibrium) structures of PSAHs $\left(\mathrm{XM}_{n+1} \mathrm{OH}_{2}^{+}\right)$with some important and chosen structural parameters in which all superalkali metal hydroxides have been protonated by adding one proton therein. Let us have a look into the optimized structures (Figure 5) and the QTAIM pictures (Figure 6) of all protonated species $\left(\mathrm{XM}_{n+1} \mathrm{OH}_{2}^{+}\right)$, it is revealed that ring diagonal NBIs exist (shown by dotted light gray color lines) between the $\mathrm{O}$ atom of the $\mathrm{OH}$ group and the $\mathrm{X}$ (F, O, and $\mathrm{N})$ atoms of the superalkali groups except the two species $\left(\mathrm{OK}_{3} \mathrm{OH}_{2}{ }^{+}\right.$and $\mathrm{NK}_{4} \mathrm{OH}_{2}{ }^{+}$), whose strength reduced going from $\mathrm{Li}$ - to $\mathrm{Na}$ - to K-related species.

For example, in the case of $\mathrm{FM}_{2} \mathrm{OH}_{2}{ }^{+}$species, one can see that during the protonation on the $\mathrm{OH}$ group, the order of the bond lengths of the $\mathrm{O}-\mathrm{H}$ bonds (decreases) and the $\mathrm{O}-\mathrm{F}$ bonds (increases) as $\mathrm{FLi}_{2} \mathrm{OH}_{2}{ }^{+}(0.967$ and $2.757 \AA) \rightarrow \mathrm{FNa}_{2} \mathrm{OH}_{2}{ }^{+}$ $(0.965$ and $3.069 \AA) \rightarrow \mathrm{FK}_{2} \mathrm{OH}_{2}{ }^{+}(0.963$ and $3.239 \AA$ ) $)$ showing decreased association of the $\mathrm{OH}$ group and superalkalis, which can further be assured by the QTAIM-based topological parameters $\left(\rho, \nabla^{2} \rho, V\right)$ of the $\mathrm{O}-\mathrm{F}$ bonds as $\mathrm{FLi}_{2} \mathrm{OH}_{2}{ }^{+}$ (0.0157, +0.052, -0.013) $\rightarrow \mathrm{FNa}_{2} \mathrm{OH}_{2}{ }^{+}(0.0078,+0.027$, $-0.006) \rightarrow \mathrm{FK}_{2} \mathrm{OH}_{2}{ }^{+}(0.0053,+0.024,-0.004)$ (in au). Similar patterns for the diagonal NBIs can also be observed for other protonated moieties as shown in Figure 5. Like the diagonal NBIs (between the $\mathrm{O}$ of the $\mathrm{OH}$ group and the $\mathrm{X}$ atoms) involved in the PSAHs $\left(\mathrm{XM}_{n+1} \mathrm{OH}_{2}^{+}\right)$, the bond lengths of the $\mathrm{X}-\mathrm{M}$ bonds also increase (i.e., decrease in the bonding interactions) going from Li- to K-related PSAHs, which can be validated by the parameters acquired from the QTAIM tool as shown in Figure 6. Interestingly as well as particularly, in the case of nonprotonated $\mathrm{FM}_{2} \mathrm{OH}$ (ring), it should be noted that the protonated $\left(\mathrm{FM}_{n+1} \mathrm{OH}_{2}^{+}\right)$form of the above moiety has two kinds of minimum energy structures (indicated by $\mathrm{FM}_{n+1} \mathrm{OH}_{2}{ }^{+}$linear and $\mathrm{FM}_{n+1} \mathrm{OH}_{2}{ }^{+}$ring $)$where the ring structure (global minima) is more stable compared to the linear structure (local minima); however, the nonprotonated $\mathrm{FM}_{2} \mathrm{OH}_{\text {linear }}$ form shows a TS having a very low imaginary frequency $(-18.9$ $\left.\mathrm{cm}^{-1}\right)$. For all the three F-substituted alkali metal cases $(\mathrm{K}, \mathrm{Na}$, and $\mathrm{Li}$ ), both protonated equilibrium structures (linear and ring) consisting of the same molecular formula $\left(\mathrm{FM}_{2} \mathrm{OH}_{2}{ }^{+}\right)$, their pictures are shown in Figure 5 indicated by double-headed colored arrow.

Using the electronic structure calculation method, precise gasphase PA and useful information on the structure of the base and its conjugate acid are obtained, and theoretically calculated PAs are more accurate than the relative values. In acquiring the PA and GB parameters for the $\mathrm{XM}_{n+1} \mathrm{OH}$, a hypothetical protonation reaction has been highlighted in the earlier section (Theory and Computations). To vindicate the existing patterns in the basicity features, it is important to examine the alterations in relevant structural parameters and bond lengths induced by protonation. Very interestingly, upon the protonation, the $\mathrm{O}-\mathrm{M}$ bond lengths (where $\mathrm{M}=\mathrm{K}, \mathrm{Na}$, and $\mathrm{Li}$ ) get elongated in all the $\mathrm{XM}_{n+1} \mathrm{OH}_{2}{ }^{+}$species; for instance, in the $\mathrm{KOH}$ and $\mathrm{KOH}_{2}{ }^{+}$, these are 2.244 and $2.629 \AA$, respectively and the change in $\mathrm{O}-\mathrm{K}$ $(\Delta \mathrm{O}-\mathrm{K})$ is $0.385 \AA$ and similarly the change $\mathrm{O}-\mathrm{K}(\Delta \mathrm{O}-\mathrm{K})$ is $0.561 \AA$ in the case going from $\mathrm{NK}_{4} \mathrm{OH}(2.446 \AA)$ to $\mathrm{NK}_{4} \mathrm{OH}_{2}{ }^{+}$ (3.007 $\AA$ ). Furthermore, lighter species like the Li-related SAHs including the $\mathrm{LiOH}$ base undergo even a smaller change from $1.607 \AA$ in $\mathrm{LiOH}$ to $1.869 \AA$ in $\mathrm{LiOH}_{2}{ }^{+}$(change: $0.262 \AA$ ) or from $1.812 \AA$ in $\mathrm{NLi}_{4} \mathrm{OH}$ to $2.217 \AA$ in $\mathrm{NLi}_{4} \mathrm{OH}_{2}{ }^{+}$(change: $0.405 \AA$ ). Trends for other species are also in accordance to the above-highlighted pattern, which can be verified from the corresponding $\mathrm{O}-\mathrm{M}$ bond lengths shown in Figures 2-5. These outcomes demonstrate that the enhancement of the $\mathrm{O}-\mathrm{M}$ bond length is larger as the basicity is higher, and in general, it occurs as a consequence of a complementary ED transfer (i.e., CT) 

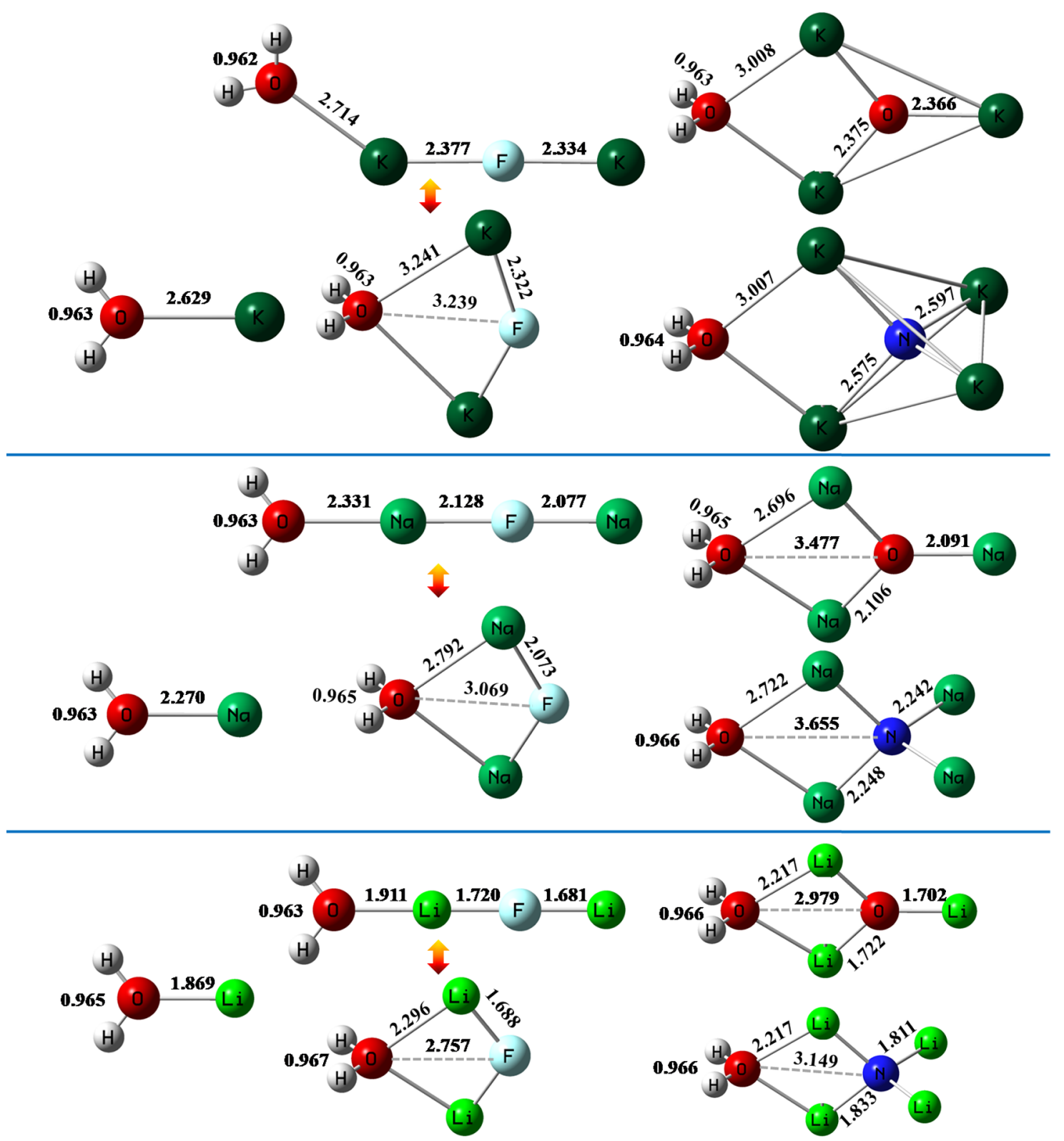

Figure 5. Equilibrium structures of protonated bases $\mathrm{LiOH}_{2}{ }^{+}, \mathrm{NaOH}_{2}{ }^{+}, \mathrm{KOH}_{2}{ }^{+}$, and $\mathrm{XM}_{n+1} \mathrm{OH}_{2}{ }^{+}\left(\mathrm{XM}_{n+1}=\left(\mathrm{FK}_{2}, \mathrm{OK}_{3}\right.\right.$, and $\left.\mathrm{NK}_{4}\right),\left(\mathrm{FNa}_{2}, \mathrm{ONa}_{3}\right.$, and $\left.\mathrm{NNa}_{4}\right)$, and $\left(\mathrm{FLi}_{2}, \mathrm{OLi}_{3}\right.$, and $\left.\left.\mathrm{NLi}_{4}\right)\right)$. The bond lengths are given in $\AA$.

from the alkali metals to the $\mathrm{OH}$ group. For instance, the $\mathrm{NBO}$ charge analysis shows that in the $\mathrm{FK}_{2} \mathrm{OH}_{2}{ }^{+}$cation, the charge on the incoming proton is only $0.468 \mathrm{e}$, whereas it changes from $-1.402 \mathrm{e}$ to $-0.933 \mathrm{e}$ on the $\mathrm{O}$ atom assuring strong electron donation. Along with the above alterations, the enhancement in the charges from $0.976 \mathrm{e}$ to $0.988 \mathrm{e}$ on the $\mathrm{K}$ atom and from $-0.973 \mathrm{e}$ to $-0.979 \mathrm{e}$ on the $\mathrm{F}$ atom can be seen from Table S1 of the Supporting Information (SI) going from nonprotonated $\mathrm{SAH}\left(\mathrm{FK}_{2} \mathrm{OH}\right)$ to protonated $\mathrm{SAH}\left(\mathrm{FK}_{2} \mathrm{OH}_{2}{ }^{+}\right)$. The $\mathrm{O}-\mathrm{H}$ stretching frequencies of the protonated as well as nonprotonated SAHs are shown in Table S1, which provide supplementary features.

The analyzed PA and GB values for all superalkali bases are tabularized in Table 2. It is worth mentioning that the basicity of newly designed SAHs (viz., the K- and Na-related SAHs) surpasses the experimental absolute PA $(1026.3 \mathrm{~kJ} / \mathrm{mol})$ and intrinsic GB $(1000 \mathrm{~kJ} / \mathrm{mol})$ values of the DMAN (the first known organic compound with high basicity), which has been accepted as a threshold for superbases. ${ }^{20}$ The PA and GB values for the $\mathrm{KOH}$ base have been calculated as 1129.2 and $1104.8 \mathrm{~kJ} /$ mol, respectively, which are in close agreement with the PA $(1101.8 \mathrm{~kJ} / \mathrm{mol})$ and $\mathbf{G B}(1075.4 \mathrm{~kJ} / \mathrm{mol})$ values reported by Lias et al. ${ }^{21}$ One can note that the PA and GB values of the $\mathrm{KOH}$ base are much lower than the corresponding values of the $\mathrm{OK}_{3} \mathrm{OH}$ (PA: $1168.4 \mathrm{~kJ} / \mathrm{mol}$ and GB: $1146.9 \mathrm{~kJ} / \mathrm{mol}$ ) (i.e., the highest one among all) and $\mathrm{NK}_{4} \mathrm{OH}($ PA: $1134.7 \mathrm{~kJ} / \mathrm{mol}$ and GB: $1117.2 \mathrm{~kJ} / \mathrm{mol}$ ) (i.e., the second highest among all) and these larger values of the $\mathrm{K}$-based SAHs $\left(\mathrm{OK}_{3} \mathrm{OH}\right.$ and $\left.\mathrm{NK}_{4} \mathrm{OH}\right)$ are indeed largely sufficient to construct these moieties, which may act as superbases.

However, conversely, the PA $(1129.2 \mathrm{~kJ} / \mathrm{mol})$ and GB $(1104.8 \mathrm{~kJ} / \mathrm{mol})$ values of $\mathrm{KOH}$ are slightly greater than those of $\mathrm{FK}_{2} \mathrm{OH}_{\text {linear }}$ (PA: $1126.9 \mathrm{~kJ} / \mathrm{mol}$ ) and significantly larger than those of $\mathrm{FK}_{2} \mathrm{OH}_{\text {ring }}$ (PA: $1103 \mathrm{~kJ} / \mathrm{mol}$ and GB: $1077.9 \mathrm{~kJ} / \mathrm{mol}$ ) superalkali bases yet it acts as a strong base. Such a finding could be elucidated by the occurrence of the $\mathrm{F}$ atom $(\chi=4$ with the 

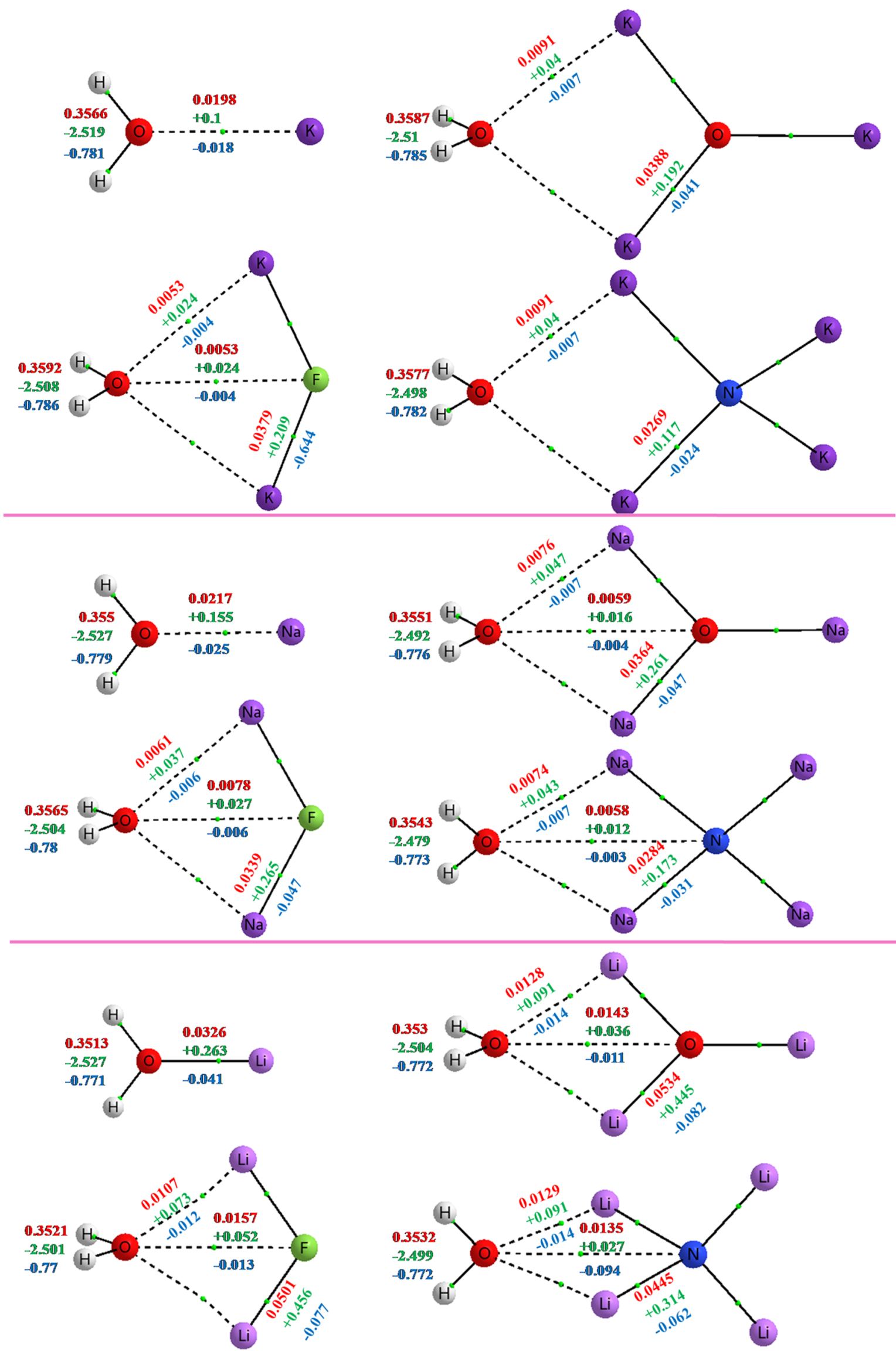

Figure 6. QTAIM pictures and topological parameters $\left(\rho, \nabla^{2} \rho, V\right)$ of the $\mathrm{MOH}_{2}{ }^{+}$and $\mathrm{XM}_{n+1} \mathrm{OH}_{2}{ }^{+}$species. 
highest electronegativity) in the $\mathrm{FK}_{2} \mathrm{OH}$ species (EA: $0.111 \mathrm{eV}$ ) having a much higher electron affinity than those of the species containing $\mathrm{O}(\chi: 3.5)$ (EA for $\mathrm{OK}_{3} \mathrm{OH}$ is $\left.0.08 \mathrm{eV}\right)$ and $\mathrm{N}(\chi: 3)$ (EA for $\mathrm{NK}_{4} \mathrm{OH}$ is $0.016 \mathrm{eV}$ ) atoms (see Table 3). It is

Table 3. IP, EA, HOMO-LUMO Gap $\left(E_{\text {gap }}\right), \chi, \boldsymbol{\eta}$, and $\boldsymbol{\mu}$ Values of $\mathrm{LiOH}, \mathrm{NaOH}, \mathrm{KOH}$, and $\mathrm{XM}_{n+1} \mathrm{OH}$ Species $\left(\mathrm{XM}_{n+1}\right.$ $=\mathrm{FK}_{2}, \mathrm{OK}_{3}, \mathrm{NK}_{4}, \mathrm{FNa}_{2}, \mathrm{ONa}_{3}, \mathrm{NNa}_{4}, \mathrm{FLi}_{2}, \mathrm{OLi}_{3}$, and $\left.\mathrm{NLi}_{4}\right)^{a}$

\begin{tabular}{lclclcl}
\multicolumn{1}{c}{ species } & IP & EA & $E_{\text {gap }}$ & $\chi$ & $\eta$ & $\mu$ \\
$\mathrm{KOH}$ & 8.78 & 0.179 & 8.601 & 4.48 & 4.301 & 7.683 \\
$\mathrm{FK}_{2} \mathrm{OH}$ & 9.458 & 0.111 & 9.347 & 4.785 & 4.674 & 1.14 \\
$\mathrm{OK}_{3} \mathrm{OH}$ & 5.788 & 0.08 & 5.708 & 2.934 & 2.854 & 8.111 \\
$\mathrm{NK}_{4} \mathrm{OH}$ & 3.322 & 0.016 & 3.306 & 1.669 & 1.653 & 0.029 \\
$\mathrm{NaOH}$ & 9.071 & 0.315 & 8.756 & 4.693 & 4.378 & 7.057 \\
$\mathrm{FNa}_{2} \mathrm{OH}$ & 10.19 & 0.14 & 10.05 & 5.165 & 5.025 & 1.616 \\
$\mathrm{ONa}_{3} \mathrm{OH}$ & 6.598 & 0.149 & 6.449 & 3.374 & 3.225 & 7.172 \\
$\mathrm{NNa}_{4} \mathrm{OH}$ & 4.743 & 0.021 & 4.722 & 2.382 & 2.361 & 5.147 \\
$\mathrm{LiOH}$ & 10.23 & 0.127 & 10.103 & 5.179 & 5.052 & 4.783 \\
$\mathrm{FLi}_{2} \mathrm{OH}$ & 11.329 & 0.193 & 11.136 & 5.761 & 5.568 & 1.582 \\
$\mathrm{OLi}_{3} \mathrm{OH}$ & 8.242 & 0.066 & 8.176 & 4.154 & 4.088 & 5.213 \\
$\mathrm{NLi}_{4} \mathrm{OH}$ & 5.638 & 0.005 & 5.633 & 2.822 & 2.817 & 4.962
\end{tabular}

${ }^{a} \mathrm{IP}, \mathrm{EA}, \chi$, and $\eta$ values are in $\mathrm{eV}$ and $\mu$ is in Debye.

interesting to note that the $\mathrm{FK}_{2} \mathrm{OH}_{\text {linear }}$ species have a slightly smaller PA value $(1126.9 \mathrm{~kJ} / \mathrm{mol})$ than that of the $\mathrm{KOH}(1129.3$ $\mathrm{kJ} / \mathrm{mol})$ while the $\mathbf{G A}(1114.3 \mathrm{~kJ} / \mathrm{mol})$ value is greater than that of the fundamental $\mathrm{KOH}$ base $(1104.8 \mathrm{~kJ} / \mathrm{mol})$.

A similar observation regarding the $\mathbf{P A}$ and $\mathbf{G B}$ values finding can be seen for the $\mathrm{XNa}_{n+1} \mathrm{OH}_{2}^{+}$(protonated) species. Like the $\mathrm{OK}_{3} \mathrm{OH}$ and $\mathrm{NK}_{4} \mathrm{OH}$ SAHs, the basicity parameters of the $\mathrm{ONa}_{3} \mathrm{OH}$ (PA: $1106.2 \mathrm{~kJ} / \mathrm{mol}$ and GB: $1081.5 \mathrm{~kJ} / \mathrm{mol}$ ) and $\mathrm{NNa}_{4} \mathrm{OH}$ (PA: $1094.9 \mathrm{~kJ} / \mathrm{mol}$ and GB: $1079.8 \mathrm{~kJ} / \mathrm{mol}$ ) moieties are higher than those in the $\mathrm{NaOH}$ base (PA: 1092.6 $\mathrm{kJ} / \mathrm{mol}$ and GB: $1066.4 \mathrm{~kJ} / \mathrm{mol}$ ) as well as $\mathrm{FNa}_{2} \mathrm{OH}_{\text {ring }}$ (PA: $1034.1 \mathrm{~kJ} / \mathrm{mol}$ and GB: $1008.4 \mathrm{~kJ} / \mathrm{mol}$ ) and $\mathrm{FNa}_{2} \mathrm{OH}_{\text {linear }}$ (PA: $1073.5 \mathrm{~kJ} / \mathrm{mol}$ and $1056.5 \mathrm{~kJ} / \mathrm{mol}$ ) SAHs. The calculated PA and GB values of the $\mathrm{NaOH}$ base are in general agreement with the experimental values (PA: $1071.8 \mathrm{~kJ} / \mathrm{mol}$ and GB: $1044.8 \mathrm{~kJ} /$ mol). As the PA and GB values for all Na-related SAHs including the $\mathrm{NaOH}$ go beyond the threshold PA and GB values of the DMAN, ${ }^{20}$ these SAHs show superbasicity character. Similar to the K-related $\left(\mathrm{FK}_{2} \mathrm{OH}\right)$ SAHs, this outcome could be explicated by the presence of the most electronegative $\mathrm{F}$ atom in the $\mathrm{FNa}_{2} \mathrm{OH}$ moiety having a much higher EA value $(0.14 \mathrm{eV})$ than that in the $\mathrm{NNa}_{4} \mathrm{OH}$ base (EA: 0.021); however, the EA value $0.149 \mathrm{eV}$ in the case of the $\mathrm{ONa}_{3} \mathrm{OH}$ species.

Moreover, a clear picture of the protonated forms of the $\mathrm{Li}$ based SAHs $\mathrm{XLi}_{n+1} \mathrm{OH}_{2}{ }^{+}\left(\mathrm{FLi}_{2} \mathrm{OH}_{2}{ }^{+}, \mathrm{OLi}_{3} \mathrm{OH}_{2}{ }^{+}\right.$, and $\mathrm{NLi}_{4} \mathrm{OH}_{2}^{+}$) can be seen in Figure 5 along with their optimized parameters; however, except for the $\mathrm{NLi}_{4} \mathrm{OH}$ and $\mathrm{OLi}_{3} \mathrm{OH}$ moieties, the PA and GB values for all Li-related species which are smaller than the threshold superbasicity of the DMAN compound taken as a reference. One should note that in terms of the PA and GB values, the basicity of the $\mathrm{NLi}_{4} \mathrm{OH}$ (PA: 1047.7 $\mathrm{kJ} / \mathrm{mol}$ and GB: $1021.5 \mathrm{~kJ} / \mathrm{mol}$ ) is $21.4 \mathrm{~kJ} / \mathrm{mol}$ and $21.5 \mathrm{~kJ} / \mathrm{mol}$ larger than those of the reference species (DMAN) (PA: 1026.3 $\mathrm{kJ} / \mathrm{mol}$ and GB: $1000 \mathrm{~kJ} / \mathrm{mol}$ ), whereas the $\mathrm{OLi}_{3} \mathrm{OH}$ (PA: $1027.4 \mathrm{~kJ} / \mathrm{mol}$ and GB: $1001.7 \mathrm{~kJ} / \mathrm{mol}$ ) has a very close basicity to those of the DMAN species. Based on the above findings, the $\mathrm{OLi}_{3} \mathrm{OH} \mathrm{SAH}$ falls in border line of the superbasicity feature. Remarkably, the $\mathrm{FLi}_{2} \mathrm{OH}$-related species $\left(\mathrm{FLi}_{2} \mathrm{OH}_{\text {linear }}\right.$ : PA: $990.3 \mathrm{~kJ} / \mathrm{mol}$ and GB: $972.4 \mathrm{~kJ} / \mathrm{mol}$ and $\mathrm{FLi}_{2} \mathrm{OH}_{\text {ring }}$ : PA: 939.8
$\mathrm{kJ} / \mathrm{mol}$ and GB: $912.3 \mathrm{~kJ} / \mathrm{mol}$ ) have been found to be weaker bases compared to the $\mathrm{LiOH}$ (PA: $1001.3 \mathrm{~kJ} / \mathrm{mol}$ and GB: 975.9 $\mathrm{kJ} / \mathrm{mol}$ ), $\mathrm{OLi}_{3} \mathrm{OH}$, and $\mathrm{NLi}_{4} \mathrm{OH}$, which seems to be due to the presence of the $\mathrm{F}$ atom (the most electronegative) that is responsible for its higher EA value $(0.193 \mathrm{eV})$ in the $\mathrm{FLi}_{2} \mathrm{OH}$ among all the Li-related species.

Finally, a relative comparison is carried out among all the K-, $\mathrm{Na}$ - and Li-related species. The order of the basicity (PA, GB) for the fundamental bases is $\mathrm{KOH}(1129.2,1104.8)>\mathrm{NaOH}$ $(1092.6,1066.4)>\mathrm{LiOH}(1001.3,975.9)(\mathrm{in} \mathrm{kJ} / \mathrm{mol})$ in which the former two fundamental bases exceed the basicity capability of the Alder's DMAN organic base. Afterward, by looking into the basicity nature of the O-substituted SAHs, a similar trend for the basicity parameters (PA, GB) can be seen as $\mathrm{OK}_{3} \mathrm{OH}$ $(1168.4,1146.9)>\mathrm{ONa}_{3} \mathrm{OH}(1106.2,1081.5)>\mathrm{OLi}_{3} \mathrm{OH}$ $(1027.4,1001.7)$ (in kJ/mol) in which the former two $\left(\mathrm{OK}_{3} \mathrm{OH}\right.$ and $\left.\mathrm{ONa}_{3} \mathrm{OH}\right)$ are the strongest superbases among their related $\mathrm{K}$ - and Na-related species, respectively (noting that $\mathrm{OK}_{3} \mathrm{OH}$ is the strongest superbase among all the moieties), whereas the latter one $\left(\mathrm{OLi}_{3} \mathrm{OH}\right)$ is the second strongest base among its $\mathrm{Li}$ related species. In the case of the family of $\mathrm{NM}_{4} \mathrm{OH}$ SAHs, the pattern for the order of basicity is $\mathrm{NK}_{4} \mathrm{OH}(1134.7,1117.2)>$ $\mathrm{NNa}_{4} \mathrm{OH}(1094.9,1079.8)>\mathrm{NLi}_{4} \mathrm{OH}(1047.7,1021.5)($ in kJ/ $\mathrm{mol}$ ) in which the $\mathbf{P A}$ and $\mathbf{G B}$ values of $\mathrm{NK}_{4} \mathrm{OH}$ are approximately $(87 \mathrm{~kJ} / \mathrm{mol}, 95.7 \mathrm{~kJ} / \mathrm{mol})$ far greater than those of the $\mathrm{NLi}_{4} \mathrm{OH}$ base, showing its superbasicity nature.

The $\mathrm{FM}_{2} \mathrm{OH}$-related series also give similar trends like all the above-highlighted ones where the F-substituted K-related linear (PA: 1126.9 and GB: 1114.8) and ring (PA: 1103 and GB: 1077.9) (in $\mathrm{kJ} / \mathrm{mol}$ ) bases are stronger than the Na-related linear (PA: 1073.5 and GB: 1056.5) and ring (PA: 1034.1 and GB:1008.1) bases as well as much stronger than the first reported DMAN organic superbase (PA: 1026.3 and GA: 1000), while the F-associated Li-related both linear (PA: $990.3 \mathrm{~kJ} / \mathrm{mol}$ and GB: $972.4 \mathrm{~kJ} / \mathrm{mol}$ ) and ring (PA: $939.8 \mathrm{~kJ} / \mathrm{mol}$ and GB: $912.3 \mathrm{~kJ} / \mathrm{mol}$ ) bases are even weaker bases than the DMAN species.

Frontier Molecular Orbital (FMO). An energy parameter (here referred to as $E_{\text {gap }}$ ) obtained from the difference between the FMOs namely the highest occupied molecular orbital (HOMO) and the lowest unoccupied molecular orbital (LUMO) is a very valuable quantity and it plays a vital role in investigating the chemical reactivity feature. Species that are more reactive have a lower $\mathrm{E}_{\text {gap }}$ value. Some important and useful electronic parameters such as HOMO-LUMO gap $\left(\mathrm{E}_{\text {gap }}\right), \mathrm{IP}$, electron affinity (EA), absolute electronegativity $(\chi)$, chemical hardness $(\eta)$, and dipole moment $(\mu)$ are listed in Table 3. In all the cases, the F-related moieties like $\mathrm{FK}_{2} \mathrm{OH}$ (9.347 eV), $\mathrm{FNa}_{2} \mathrm{OH}(10.05 \mathrm{eV})$, and $\mathrm{FLi}_{2} \mathrm{OH}(11.136 \mathrm{eV})$ have slightly larger $E_{\text {gap }}$ values concerning their corresponding series. For example, $\mathrm{FK}_{2} \mathrm{OH}(9.347 \mathrm{eV})$ has a larger value than those $\mathrm{KOH}(8.601 \mathrm{eV})$ and its other related molecules like $\mathrm{OK}_{3} \mathrm{OH}(5.708 \mathrm{eV})$ and $\mathrm{NK}_{4} \mathrm{OH}(3.306 \mathrm{eV})$.

Such outcomes fairly demonstrate that the $\mathrm{FK}_{2} \mathrm{OH}$ SAH gets notably more stabilized compared to the $\mathrm{KOH}$ base, which appears to be because of the $\mathrm{CT}$ to the most electronegative $\mathrm{F}$ atom. From the abovementioned values, it is clear that the HOMO-LUMO gaps for the $\mathrm{KOH}$ base are larger than those of $\mathrm{OK}_{3} \mathrm{OH}$ and $\mathrm{NK}_{4} \mathrm{OH}$. Therefore, it is remarkable to mention that the outlook of the trend of the $E_{\text {gap }}$ values is $\mathrm{FK}_{2} \mathrm{OH}$ (9.347) $>\mathrm{KOH}(8.601)>\mathrm{OK}_{3} \mathrm{OH}(5.708)>\mathrm{NK}_{4} \mathrm{OH}$ (3.306) (in eV), while the order of basicity (PA, GB) for all these four species is in almost an opposite fashion as $\mathrm{FK}_{2} \mathrm{OH}(1103,1077.9)<\mathrm{KOH}$ 


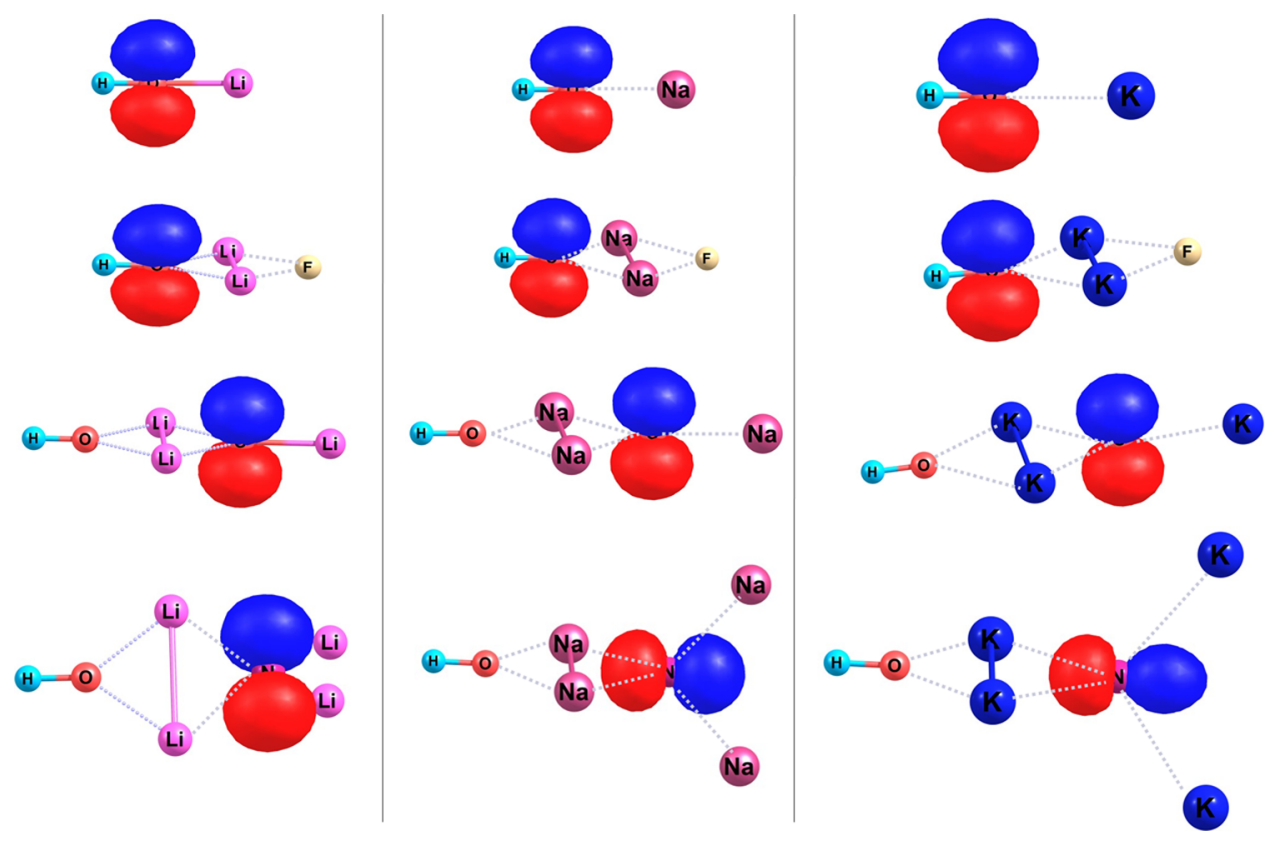

Figure 7. $\mathrm{HOMO}$ of the $\mathrm{LiOH}, \mathrm{NaOH}, \mathrm{KOH}$ (top), and $\mathrm{XM}_{n+1} \mathrm{OH}$ species $\left(\mathrm{XM}_{n+1}=\mathrm{FLi}_{2} / \mathrm{FNa}_{2} / \mathrm{FK}_{2}\left(\right.\right.$ below the top), OLi $3 / \mathrm{ONa}_{3} / \mathrm{OK}_{3}(\mathrm{above}$ the bottom), and $\mathrm{NLi}_{4} / \mathrm{NNa}_{4} / \mathrm{NK}_{4}$ (bottom)).

$(1126.9,1114.3)<\mathrm{NK}_{4} \mathrm{OH}(1134.7,1117.2)<\mathrm{OK}_{3} \mathrm{OH}$ (1168.4, 1146.9) (in $\mathrm{kJ} / \mathrm{mol}$ ). Hence, a straightforward connection between the chemical reactivity and basicity can be seen which advocates that the moieties show more basic character with a lower $E_{\text {gap }}$ value.

Using Koopmans' approximation, quantification of IP and EA is possible by considering the negative of the energy eigenvalues of the HOMO (-HOMO) and the LUMO (-LUMO) of the FMOs. Moreover, finite-difference approaches provide two very important parameters, $\chi$ and $\eta .^{53}$ It is noteworthy to mention that the order of the analyzed (IP, $\chi, \eta)$ values is $\mathrm{FK}_{2} \mathrm{OH}(9.458$, $4.785,4.674)>\mathrm{KOH}(8.78,4.48,4.301)>\mathrm{OK}_{3} \mathrm{OH}(5.788$, $2.934,2.854)>\mathrm{NK}_{4} \mathrm{OH}(3.322,1.669,1.653)($ in $\mathrm{eV})$, which are consistent with the chemical reactivity $\left(E_{\text {gap }}\right): \mathrm{FK}_{2} \mathrm{OH}(9.347)>$ $\mathrm{KOH}(8.601)>\mathrm{OK}_{3} \mathrm{OH}(5.708)>\mathrm{NK}_{4} \mathrm{OH}$ (3.306) (in eV) and also almost with the basicity (PA, GB) $\mathrm{FK}_{2} \mathrm{OH}$ (1103, $1077.9)<\mathrm{KOH}(1126.9,1114.3)<\mathrm{NK}_{4} \mathrm{OH}(1134.7,1117.2)<$ $\mathrm{OK}_{3} \mathrm{OH}(1168.4,1146.9)$ (in $\mathrm{kJ} / \mathrm{mol}$ ) of the $\mathrm{XK}_{n+1} \mathrm{OH}$ moieties. Almost reciprocal relationships can be seen between the (IP, $\chi$, and $\eta$ ) and the (PA, GB) values in the protonation reactions.

A similar trend can be observed in the case of Na-related species in which the three electronic parameters (IP, $\chi, \eta)$ follow the order $\mathrm{FNa}_{2} \mathrm{OH}(10.19,5.165,5.025)>\mathrm{NaOH}(9.071,4.693$, $4.378)>\mathrm{ONa}_{3} \mathrm{OH}(6.598,3.374,3.225)>\mathrm{NNa}_{4} \mathrm{OH}$ (4.743, $2.382,2.361$ ) (in eV), which is in accordance (connected either in proportional or reciprocal way) with the chemical reactivity $\left(E_{\text {gap }}\right): \mathrm{FNa}_{2} \mathrm{OH}(10.05)>\mathrm{NaOH}(8.756)>\mathrm{ONa}_{3} \mathrm{OH}(6.449)$ $>\mathrm{NNa}_{4} \mathrm{OH}$ (4.722) (in eV) and also almost with the basicity (PA, GB) $\mathrm{FNa}_{2} \mathrm{OH}(1073.5,1056.5)<\mathrm{NaOH}(1092.6,1066.4)$ $<\mathrm{NNa}_{4} \mathrm{OH}(1094.9,1079.8)<\mathrm{ONa}_{3} \mathrm{OH}(1106.2,1081.5)<$ (in $\mathrm{kJ} / \mathrm{mol}$ ) of the $\mathrm{XNa}_{n+1} \mathrm{OH}$ moieties; however, in the case of Li-related species, a perfect inverse correlation can be noticed for the same. One can observe that smaller $\chi$ values are associated with higher PA and GB values. The molecular dipole moments (DM) $(\mu)$ of the $\mathrm{XM}_{n+1} \mathrm{OH}$ are listed in Table 3. The computed DMs of the fundamental bases $\mathrm{KOH}, \mathrm{NaOH}$, and $\mathrm{LiOH}$ are $7.683,7.057$, and 4.783 , respectively (in Debye), which are in close proximity with the experimental findings (viz., DM for the LiOH: $4.754 \pm 0.002$ Debye). ${ }^{54}$ The DMs of the $\mathrm{OK}_{3} \mathrm{OH}$ (8.111 Debye) and $\mathrm{KOH}(7.683$ Debye) are computed to be larger than those of the $\mathrm{FK}_{2} \mathrm{OH}$ (1.14 Debye) and $\mathrm{NK}_{4} \mathrm{OH}$ (0.029), which implies that the former two species are more polarized compared to the latter two and the direction of $\mu$ can be seen from the $\mathrm{OH}$ (hydroxyl group) to the superalkalis in all cases of the $\mathrm{XM}_{n+1} \mathrm{OH}$ species.

For achieving some more insights into the electronic features of the $\mathrm{XM}_{n+1} \mathrm{OH}$ moieties, the HOMO 3D isosurface maps are plotted and shown in Figure 7. One can notice that the HOMOs are located over the atomic orbitals of the $\mathrm{O}$ atoms of the hydroxyl group $(\mathrm{OH})$ for all the $\mathrm{MOH}$ bases $(\mathrm{KOH}, \mathrm{NaOH}$, and $\mathrm{LiOH}$ ) and $\mathrm{XM}_{n+1} \mathrm{OH}$ (where $n=1$ ) superbases keeping in mind that the basicities of $\mathrm{FM}_{2} \mathrm{OH}\left(\mathrm{FK}_{2} \mathrm{OH}, \mathrm{FNa}_{2} \mathrm{OH}\right.$, and $\mathrm{FK}_{2} \mathrm{OH}$ ) are comparable to those of the $\mathrm{MOH}$ bases; however, the HOMOs of the $\mathrm{XM}_{3} \mathrm{OH}$ and $\mathrm{XM}_{4} \mathrm{OH}$ are mainly spread over in a different way. For example, the larger size of the $\mathrm{XM}_{4}$ segment of $\mathrm{XM}_{4} \mathrm{OH}$ is responsible for a more delocalized electron, which could explain well the larger basicity of the $\mathrm{XM}_{4} \mathrm{OH}$ superbases. In a similar way, the large HOMO lobes of the $\mathrm{XM}_{3} \mathrm{OH}$ species can be seen near their $\mathrm{XM}_{3}$ fragments $\left(\mathrm{OLi}_{3}, \mathrm{ONa}_{3}\right.$, and $\left.\mathrm{OK}_{3}\right)$, which could explain their stronger basicity features.

\section{CONCLUDING REMARKS}

In this study, designing and theoretical characterization of a new and novel series of $\mathrm{K}$ and Na-based SAHs have been elucidated including some highlights on the Li-related bases. The ab initio method is used to conduct an inclusive computational investigation on the basicity as well as other electronic features of the $\mathrm{XM}_{n+1} \mathrm{OH}$ SAHs. The employed ab initio findings disclose that the $\mathrm{K}$ - and Na-related SAHs have been detected as stronger bases than the $\mathrm{LiOH}$ and its SAHs. However, in the existing $\mathrm{SAH}$ examples of the strong bases and superbases, $\mathrm{OK}_{3} \mathrm{OH}$ acting as the superbase has been found to be the strongest base (in the gas phase) with the largest PA $(1168.4 \mathrm{~kJ} / \mathrm{mol})$ and GB $(1146.9 \mathrm{~kJ} / \mathrm{mol})$ values among all the probed species, which are 
much higher the threshold basicity values (PA: $1026.3 \mathrm{~kJ} / \mathrm{mol}$ and GB: $1000 \mathrm{~kJ} / \mathrm{mol}$ ) of DMAN conferred by the IUPAC. In addition, to obtain more insights into the probed SAHs, the dissociation energy, IP, EA, HOMO-LUMO gap, and $\eta$ have also been analyzed using the electronic structure calculation approach, which provides a good correlation with the basicity values (PA and GB). The NCI plot and QTAIM tools give significant information about the bonding and nonbonding features involved therein.

The design and synthesis of such inspected SAHs may pave a way for practical availing applications. As further exploration of the real-time application of superalkali-based hydroxides is required yet, the author is looking forward to a practical investigation of our predictions based on computational experiments. Moreover, theoretical exploration of the stability of superalkalis and associated species in solvents like water, ethanol, acetone, etc. would definitely be valuable as efforts still have not been paid much and access for new applications of superalkalis and related species can be created, which would be of great significance.

\section{ASSOCIATED CONTENT}

\section{(s) Supporting Information}

The Supporting Information is available free of charge at https://pubs.acs.org/doi/10.1021/acsomega.1c04395.

Natural charges on the protonated $\left(\mathrm{XM}_{n+1} \mathrm{OH}\right)$ and nonprotonated $\left(\mathrm{XM}_{n+1} \mathrm{OH}_{2}^{+}\right)$SAHs as well as the $\mathrm{O}-\mathrm{H}$ frequencies (Table S1), bond lengths of $\mathrm{O}-\mathrm{M}(\mathrm{M}=\mathrm{K}$, $\mathrm{Na}$, and $\mathrm{Li})$ in the nonprotonated $\left(\mathrm{XM}_{n+1} \mathrm{OH}\right)$ and protonated $\left(\mathrm{XM}_{n+1} \mathrm{OH}_{2}^{+}\right)$SAHs and changes therein (Table S2), and Cartesian coordinates of all the $\mathrm{K}-, \mathrm{Na}-$ and Li-related species as well as complete reference 37 (Gaussian) (PDF)

\section{Accession Codes}

$\mathrm{NCI}$ plots (2D scatter plot and 3D isosurface maps) acquired from Multiwfn, VMD, and IrfanView tools are publicly available free of charge. Gaussian 09 software has been used for the electronic structure calculations, and GaussView 6.0 was utilized for the optimized structure presentation. The AIMAll tool used in analyzing the topological parameters can be accessed by purchasing AIMAll professional from http://aim.tkgristmill. com.

\section{AUTHOR INFORMATION}

\section{Corresponding Author}

Sarvesh Kumar Pandey - Department of Inorganic and

Physical Chemistry, Indian Institute of Science Bangalore,

Bangalore 560 012, India; ๑ orcid.org/0000-0002-6315-

8118; Email: sarveshp@iisc.ac.in

Complete contact information is available at:

https://pubs.acs.org/10.1021/acsomega.1c04395

\section{Notes}

The author declares no competing financial interest.

\section{ACKNOWLEDGMENTS}

The author acknowledges the University Grant Commission (UGC), New Delhi, India for Kothari Fellowship (Award No: $\mathrm{CH} / 19-20 / 0028)$. S.K.P. is indebted for the endless help and support from Professor E. Arunan. The author acknowledges Mr. F. Jayakanth for the suggestion and help.

\section{DEDICATION}

This paper is dedicated to Professor P. v. R. Schleyer for his remarkable contribution in the field of Computational Chemistry and Professor Kaman Singh, BBAU Lucknow (A Central University), India for his notable contribution in the area of Physical Chemistry.

\section{REFERENCES}

(1) Lennon, M. A.; Bell, K. L.; Gilbody, H. B.; Hughes, J. G.; Kingston, A. E.; Murray, M. J.; Smith, F. J. Recommended Data on the Electron Impact Ionization of Atoms and Ions: Fluorine to Nickel. J. Phys. Chem. Ref. Data 1988, 17, 1285-1363.

(2) Tong, J.; Li, Y.; Wu, D.; Wu, Z. J. Theoretical Study on Polynuclear Superalkali Cations with Various Functional Groups as the Central Core. Inorg. Chem. 2012, 51, 6081-6088.

(3) Hou, N.; Li, Y.; Wu, D.; Li, Z. R. Do Nonmetallic Superalkali Cations Exist? Chem. Phys. Lett. 2013, 575, 32-35.

(4) Rehm, E.; Schleyer, P. v. R.; Boldyrev, A. I. Ab Initio Study of Superalkalis. First Ionization Potentials and Thermodynamic Stability. Inorg. Chem. 1992, 31, 4834-4842.

(5) Gutsev, G. L.; Boldyrev, A. I. DVM X $\alpha$ Calculations on the Electronic Structure of "Superalkali" Cations. Chem. Phys. Lett. 1982, 92, 262-266.

(6) Sun, W. M.; Fan, L. T.; Li, Y.; Liu, J. Y.; Wu, D.; Li, Z. R. On the Potential Application of Superalkali Clusters in Designing Novel Alkalides with Large Nonlinear Optical Properties. Inorg. Chem. 2014, 53, 6170-6178.

(7) Lievens, P.; Thoen, P.; Bouckaert, S.; Bouwen, W.; Vanhoutte, F.; Weidele, H.; Silverans, R. E.; Navarro-Vazquez, A.; Schleyer, P. v. R. Ionization Potentials of $\mathrm{LinO}(2 \leq \mathrm{n} \leq 70)$ Clusters: Experiment and Theory. J. Chem. Phys. 1999, 110, 10316-10329.

(8) Sun, W. M.; Wu, D. Recent Progress on the Design, Characterization, and Application of Superalkalis. Chem. - Eur. J. 2019, 25, 9568-9579.

(9) Giri, S.; Behera, S.; Jena, P. Superalkalis and Superhalogens as Building Blocks of Supersalts. J. Phys. Chem.A 2014, 118, 638-645.

(10) Srivastava, A. K.; Pandey, S. K.; Misra, N. Prediction of Superalkali@C60 Endofullerenes, Their Enhanced Stability and Interesting Properties. Chem. Phys. Lett. 2016, 655-656, 71-75.

(11) Bengtsson, L.; Holmberg, B.; Ulvenlund, S. Liz F+ and LizOH+ in Molten Alkali-Metal Nitrate. Inorg. Chem. 1990, 29, 3615-3618.

(12) Yokoyama, K.; Haketa, N.; Tanaka, H.; Furukawa, K.; Kudo, H. Ionization Energies of Hyperlithiated $\mathrm{Li}_{2} \mathrm{~F}$ Molecule and Li F-1 $(n=$ 3,4) clusters. Chem. Phys. Lett. 2000, 330, 339-346.

(13) Veličković, S. R.; Veljković, F. M.; Perić-Grujić, A. A.; Radak, B. B.; Veljković, M. V. Ionization Energies of $\mathrm{K}_{2} \mathrm{X}(\mathrm{X}=\mathrm{F}, \mathrm{Cl}, \mathrm{Br}, \mathrm{I})$ Clusters. Rap. Comm. Mass Spect. 2011, 25, 2327-2332.

(14) Dao, P. D.; Peterson, K. I.; Castleman, A. W. The Photoionization of Oxidized Metal Clusters. J. Chem. Phys. 1984, 80, 563564.

(15) Hampe, O.; Koretsky, G. M.; Gegenheimer, M.; Huber, C.; Kappes, M. M.; Gauss, J. On the Ground and Electronically Excited States of $\mathrm{Na}_{3} \mathrm{O}$ : Theory and Experiment. J. Chem. Phys. 1997, 107, 7085-7095.

(16) Wang, D.; Graham, J. D.; Buytendyk, A. M.; Bowen, K. H. Photoelectron Spectroscopy of the Molecular Anions, $\mathrm{Li}_{3} \mathrm{O}^{-}$and $\mathrm{Na}_{3} \mathrm{O}^{-}$. J. Chem. Phys. 2011, 135, 164308/1-164308/5.

(17) Ying, L.; Di, W.; Zhi-Ru, L.; Chia-Chung, S. Structural and Electronic Properties of Boron-Doped Lithium Clusters: Ab Initio and DFT Studies. J. Comput. Chem. 2007, 28, 1677-1684.

(18) Searles, S. K.; Dzidic, I.; Kebarle, P. Proton Affinities of the Alkali Hydroxides. J. Am. Chem. Soc. 1969, 91, 2810-2811.

(19) Caubère, P. Unimetal Super Bases. Chem. Rev. eviews 1993, 93, 2317-2334.

(20) Alder, R. W.; Bowman, P. S.; Steele, W. R. S.; Winterman, D. R The Remarkable Basicity of 1,8-Bis(Dimethylamino)Naphthalene. Chem. Comm. 1968, 723-225. 
(21) Hunter, E. P. L.; Lias, S. G. Evaluate Gas Phase Basicities and Proton Affinity of Molecules. Pdf. J. Phys. Chem. Ref. Data 1998, 27, 413-656.

(22) Lias, S.; Bartmess, J.; Liebman, J.; Holmes, J.; Levin, R.; Mallard, W. Gas-Phase Ion and Neutral Thermochemistry. J. Phys. Chem. Ref. Data 1988, 1-861.

(23) Jansen, V. M. Neue Untersuchungen an $\mathrm{Na}_{3} \mathrm{NO}_{3}$. Z. Anorg. Allg. Chem. 1977, 435, 13-20.

(24) Honea, E. C.; Homer, M. L.; Labastie, P.; Whetten, R. L. Localization of an Excess Electron in Sodium Halide Clusters. Phys. Rev. Lett. Revi. Lett. 1989, 63, 394-397.

(25) Honea, E. C.; Homer, M. L.; Whetten, R. L. Electron Binding and Stability of Excess-Electron Alkali Halide Clusters: Localization and Surface States. Phys. Rev. BReview B 1993, 47, 7480-7493.

(26) Nešković, O. M.; Veljković, M. V.; Veličković, S. R.; Petkovska, L. T.; Perić-Grujić, A. A. Ionization Energies of Hypervalent Li2F, Li2Cl and $\mathrm{Na} 2 \mathrm{Cl}$ Molecules Obtained by Surface Ionization Electron Impact Neutralization Mass Spectrometry. Rap. Comm. Mass Spect. 2003, 17, 212-214.

(27) Willis, M.; Götz, M.; Kandalam, A. K.; Ganteför, G. F.; Jena, P. Hyperhalogens: Discovery of a New Class of Highly Electronegative Species. Angew. Chem., Int. Ed. 2010, 49, 8966-8970.

(28) Tong, J.; Wu, Z.; Li, Y.; Wu, D. Prediction and Characterization of Novel Polynuclear Superalkali Cations. Dalton Trans. 2013, 42, 577584.

(29) Yang, H.; Li, Y.; Wu, D.; Li, Z. R. Structural Properties and Nonlinear Optical Responses of Superatom Compounds $\mathrm{BF}_{4}-\mathrm{M}(\mathrm{M}=$ $\mathrm{Li}, \mathrm{FLi}_{2}, \mathrm{OLi}_{3}, \mathrm{NLi}_{4}$ ). Int. J. Quantum Chem. 2012, 112, 770-778.

(30) Srivastava, A. K.; Misra, N. Superalkali-Hydroxides as Strong Bases and Superbases. New J. Chem. 2015, 39, 6787-6790.

(31) Awasthi, S.; Gaur, J. K.; Pandey, S. K.; Bobji, M. S.; Srivastava, C. High-Strength, Strongly Bonded Nanocomposite Hydrogels for Cartilage Repair. ACS Appl. Mater. Interfaces 2021, 13, 24505-24523.

(32) Pandey, S. K.; Arunan, E. Effects of Multiple OH/SH Substitution on the H-Bonding/Stability versus Aromaticity of Benzene Rings: From Computational Insights. ChemistrySelect 2021, 6, 51205139.

(33) Pandey, S. K. Computational Study on the Structure, Stability, and Electronic Feature Analyses of Trapped Halocarbons inside a Novel Bispyrazole Organic Molecular Cage. ACS Omega 2021, 6, 11711-11728

(34) Mehdi, S. H.; Ghalib, R. M.; Awasthi, S.; Alshahateet, S. F.; Hashim, R.; Sulaiman, O.; Pandey, S. K. Synthesis, Characterization, Crystal Structure, and Stability of 2-(5,5-Dimethyl-3-Oxocyclohex-1En-1-Yl) Hydrazinecarbothioamide: A Combined Experimental and Theoretical Study. ChemistrySelect 2017, 2, 6699-6709.

(35) Sullivan, M. B.; Iron, M. A.; Redfern, P. C.; Martin, J. M. L.; Curtiss, L. A.; Radom, L. Heats of Formation of Alkali Metal and Alkaline Earth Metal Oxides and Hydroxides: Surprisingly Demanding Targets for High-Level Ab Initio Procedures. J. Phys. Chem. A 2003, 107, 5617-5630.

(36) Møller, C.; Plesset, M. S. Note on an Approximation Treatment for Many-Electron Systems. Phy. Rev. 1934, 46, 618-622.

(37) Frisch, M. J., Trucks, G. W., Schlegel, H. B., Scuseria, G. E., Robb, M. A., Cheeseman, J. R., Scalmani, G., Barone, V., Mennucci, B., Petersson, G. A., Nakatsuji, H., Caricato, M., Li, X., Hratchian, H. P., Izmaylov, A. F., Bloino, J., Zheng, G., Sonnenberg, J. L., Had, M., Fox, D. J.Gaussian 09, Revision D.012013, Gaussian, Inc., Wallingford CT.

(38) Topol, I. A.; Tawa, G. J.; Burt, S. K.; Rashin, A. A. Calculation of Absolute and Relative Acidities of Substituted Imidazoles in Aqueous Solvent. J. Phys. Chem. A 1997, 101, 10075-10081.

(39) Bader, R. F. W.Atoms in Molecules: A Quantum Theory; Oxford University Press: Oxford, 1990.

(40) Keith, T. A.; Gristmill, T. K.AIMAll (Version 14.06.21); Overland Park, KS, USA, 2014.

(41) Reed, A. E.; Curtiss, L. A.; Weinhold, F. Intermolecular Interactions from a Natural Bond Orbital, Donor-Acceptor Viewpoint. Chem. Rev. 1988, 88, 899-926.
(42) Contreras-García, J.; Johnson, E. R.; Keinan, S.; Chaudret, R.; Piquemal, J. P.; Beratan, D. N.; Yang, W. NCIPLOT: A Program for Plotting Noncovalent Interaction Regions. J. Chem. Theory Comput. 2011, 7, 625-632.

(43) Lu, T.; Chen, F. Multiwfn: A Multifunctional Wavefunction Analyzer. J. Comput. Chem. 2012, 33, 580-592.

(44) Zhang, Z.; Chen, H. Superalkali $\mathrm{NM}_{4}(\mathrm{M}=\mathrm{Li}, \mathrm{Na}, \mathrm{K})$ : Stabilities and Electronic Structures. Phys. Lett. A 2019, 383, No. 125952.

(45) Puleo, T. R.; Sujansky, S. J.; Wright, S. E.; Bandar, J. S. Organic Superbases in Recent Synthetic Methodology Research. Chem. - Eur. J. 2021, 27, 4216-4229.

(46) Pozharskii, A. F.; Ozeryanskii, V. A. Proton Sponges and Hydrogen Transfer Phenomena. Mendeleev Commun. 2012, 22, 117124.

(47) Pearson, E. F.; Winnewisser, B. P.; Trueblood, M. B. Millimeter Wave Spectrum of Excited Vibrational States of Potassium Hydroxide. KOH and KOD. J. Chem. Phys. 1976, 31, 826.

(48) Yadav, P.; Pandey, S. K.; Shama, P.; Kumar, S.; Banerjee, M.; Sethi, A. Experimental and Theoretical Investigation of Synthesized Pregnenolone Derivatives via Palladium Catalyzed Cross Coupling Reactions, Their Anticancer Activity against Lung Cancer Cells. J. Mol. Struct. 2021, 1245, No. 131115.

(49) Cremer, D.; Kraka, E. A Description of the Chemical Bond in Terms of Local Properties of Electron Density and Energy. Croat. Chem. Acta 1984, 57, 1259-1281.

(50) Korabel'Nikov, D. V.; Zhuravlev, Y. N. The Nature of the Chemical Bond in Oxyanionic Crystals Based on QTAIM Topological Analysis of Electron Densities. RSC Adv. 2019, 9, 12020-12033.

(51) Graner, G.; Hirota, E.; Iijima, T.; Kuchitsu, K.; Ramsay, D. A.; Vogt, J.; Vogt, N.Structure of Free Polyatomic Molecules - Basic Data; Springer Berlin: Berlin, 1998.

(52) McNaughton, D.; Tack, L. M.; Kleibömer, B.; Godfrey, P. D. Rotational Spectrum and Bending Potential of LiOH: A Semirigid Bender Analysis. Struct. Chem. 1994, 5, 313-319.

(53) Parr, R. G.; Pearson, R. G. Absolute Hardness: Companion Parameter to Absolute Electronegativity. J. Am. Chem. Soc. 1983, 105, $7512-7516$.

(54) Landolt, H.; Bornstein, R.Numerical Data and Functional Relationships in Science and Technology, New Series, II/14a; Springer Verlag Inc.: Heidelberg, 1982. 